Calix[4]arene sulfonate hosts selectively modified on the upper rim: A study of nicotine binding strength and geometry

Zoey Warmerdam ${ }^{1}$, Bianca E. Kamba ${ }^{2}$, Alok Shaurya ${ }^{1}$, XuXin Sun ${ }^{1}$, Mary Maguire ${ }^{1}$, Fraser $\operatorname{Hof}^{1 *}$

1. Department of Chemistry, University of Victoria, 3800 Finnerty Rd, V8W3V6 Victoria, BC, Canada

2. Department of Structural and Medicinal Biochemistry, Universität Duisburg Essen, Universitätstrasse 2, 45141 Essen, Germany

*fhof@uvic.ca, Twitter@Hof_group_news 


\title{
Calix[4]arene sulfonate hosts selectively modified on the upper rim: A study of nicotine binding strength and geometry
}

\begin{abstract}
We present the synthesis and structure-activity relationships of sulfonatocalix[4]arene hosts bearing novel substitutions. The calix[4]arenes are modified on the upper rim at either one or two of the phenolic units, where the dual modifications are introduced selectively on neighboring or opposing phenols. The calix[4]arenes are mono- or di-functionalized with nitro or formyl groups, with the remaining upper-rim sites in all cases occupied by sulfonates. Equilibrium association constants were determined between each host and the guests nicotine, nornicotine, and cotinine. Indicator displacement-based binding studies show that nicotine binds most strongly to the different members of the library followed by nornicotine, whereas cotinine displays weak to no binding. NMR titrations were carried out with nicotine and show different host-guest interaction geometries for the formyl-calix[4]arenes versus the nitro-calix[4]arenes.
\end{abstract}

Keywords: calixarenes, macrocycles, host-guest chemistry, NMR

\section{Introduction}

Calix[n]arenes are macrocycles with multiple characteristics that make them effective supramolecular hosts.[1] They can be synthesized with a different number ' $n$ ' of phenolic units, often $n=4,5,6$ or 8 , which alters the binding pocket size. Their hydrophobic cavity can easily be modified on the upper and lower rims to introduce new functionality.[2] Unlike the outward-facing synthetic modifications that are readily accessible on other macrocycles, $[3,4,5]$ the new groups installed on the upper rim of a calixarene directly line the binding pocket, and can change the potency and guest selectivity of the hosts. [6, $7,8,9]$ Due to their varied functionality, molecular recognition within calixarenes takes place via many kinds of non-covalent interactions, including electrostatics, the hydrophobic effect, hydrogen bonding, van der Waals forces, $\pi-\pi$ interactions, cation- $\pi$ interactions, and more.[10] 
Sulfonated calix[n]arenes are well suited to host biological partners.[11] Calix [n]arenes show low to no toxicity in animal models $[12,13]$ and site-selective functionalization[14, 15] gives rise to new binding properties. Calix[4]arenes have four phenolic units linked by four methylene groups and routes for their regioselective functionalization are established. The small hydrophobic cavity (an inner diameter $=3.8$ $\AA$ [16]) and facile sulfonation on the upper rim makes them well suited to interact with small, cationic, hydrophobic guests.

We've chosen nicotine as a representative model drug in this work because of its cationic amine and overall hydrophobicity, which make it likely to be a good guest for calix[4]arene hosts. Nicotine is a ubiquitous drug and a well-studied molecule, although it has not been studied as a guest for calixarene-type hosts. Binding studies with nicotine have mostly been completed with cucurbit[n]urils and $\beta-C y c l o d e x t r i n$. Depending on the modification of the hosts, and $\mathrm{pH}$ and temperature of the binding assays, the cucurbituril hosts have association constants that range from $3.6 \times 10^{2}-6.5 \times 10^{4} \mathrm{M}^{-1},[17,18]$ while $\beta$ Cyclodextrin has shown $\mathrm{K}_{\text {assoc }}$ values of 14-260 $\mathrm{M}^{-1}$.[19] Using nicotine in binding studies with (novel) calix[4] arene hosts provides fundamental insight on binding strength, stoichiometry and binding motifs of small molecule host-guest complexes. In addition to nicotine, its two metabolites nornicotine and cotinine[20] are also studied.

In this work we report the nicotine binding properties of new calix[4]arenes that combine sulfonates and one or two other introduced functional groups on the upper rim. One of the key issues that we address is the selective difunctionalization of the neighbouring or opposing phenolic units, resulting in a 1,2- or 1,3-substituted regioisomers (Figure 1). We also explore how changes between relatively similar functional groups can drive unexpected differences in the binding orientations for a given guest. Although this work specifically focuses on nicotine and its metabolites, the new 
hosts set the stage for further elaborations in order to target a broad range of other small cationic molecules including amino acids, natural metabolites, drugs, and drug metabolites.

\section{Materials and methods}

\section{General}

${ }^{1} \mathrm{H}$ and ${ }^{13} \mathrm{C}$ NMR were recorded on a Bruker Avance Neo $500 \mathrm{MHz}$ spectrometer unless otherwise indicated, and processed with MestReNova by Mestrelab Research S.L and TopSpin 3.5. Deuterated solvents were purchased from Sigma Aldrich. Melting points are uncorrected and were collected on a Gallenkamp Melting Point apparatus. High resolution mass spectra of novel compounds were collected on a Thermo Scientific Ultimate 3000 ESI-Orbitrap Exactive. Infrared (IR) spectra were acquired using a Perkin Elmer 1000 FT-IR spectrometer. Data are represented as follows: frequency of absorption $\left(\mathrm{cm}^{-1}\right)$, intensity of absorption $(\mathrm{s}=$ strong, $\mathrm{m}=$ medium, $\mathrm{w}=\mathrm{weak}, \mathrm{br}=$ broad $)$. Compound nicknames below are numbered based on the four benzene positions around the macrocycle, rather than by IUPAC naming schemes, in order to give an accessible description of different regioismeric structures.

\section{Synthesis}

\section{1,3-diformyl-2,4-dibenzoylcalix[4]arene (Compound 10)}

Compound 8 [21] (1.0 g, $1.58 \mathrm{mmol})$ and HMTA (1.99 g, $14.2 \mathrm{mmol})$ were added to TFA $(20 \mathrm{~mL})$ and the reaction was heated to $70^{\circ} \mathrm{C}$ overnight. The reaction was quenched with water and the precipitate collected by vacuum filtration, yielding compound $\mathbf{1 0}$ as a pale yellow solid $(0.849 \mathrm{~g}, 78 \%)$ that was carried forward without further purification. 


\section{1,3-dinitro-2,4-dibezoylcalix[4]arene (Compound 12)}

Compound 8 [21] (1.0 g, $1.58 \mathrm{mmol})$ and potassium nitrate $(0.399 \mathrm{~g}, 3.95 \mathrm{mmol})$ were added to dry round bottom flask. The system was evacuated and flushed three times with nitrogen. Dry acetonitrile $(100 \mathrm{~mL})$ was added via cannula. Boron trifluoride diethyl etherate $(0.561 \mathrm{~g}, 3.95 \mathrm{mmol})$ was added via syringe and the reaction was stirred under nitrogen atmosphere at room temperature for $48 \mathrm{~h}$. The reaction was quenched with hydrochloric acid (1 M) and the precipitate was collected by vacuum filtration, yielding compound 12 as a yellow solid $(0.822 \mathrm{~g}, 72 \%)$ that was carried forward without further purification.

\section{1,3-diformyl-calix[4]arene (Compound 14)}

Compound $10(0.85 \mathrm{~g}, 1.23 \mathrm{mmol})$ was added to methanol $(50 \mathrm{~mL})$. Sodium hydroxide $(0.74,18.4 \mathrm{mmol})$ was added to the suspension. The solution was heated at $70^{\circ} \mathrm{C}$ for 4 hours. The reaction was quenched with hydrochloric acid $(1 \mathrm{M})$ and the precipitate was collected by vacuum filtration. The crude product was triturated in hot hexanes to remove the benzoic acid, yielding compound 14 as a dark brown/purple solid $(0.468 \mathrm{~g}, 79 \%) .{ }^{1} \mathrm{H}$ $\operatorname{NMR}\left(300 \mathrm{MHz}, \mathrm{CDCl}_{3}\right): \delta 10.18(\mathrm{~s}, 4 \mathrm{H}), 9.73(\mathrm{~s}, 2 \mathrm{H}), 7.61(\mathrm{~s}, 4 \mathrm{H}), 7.13(\mathrm{~d}, J=7.5 \mathrm{~Hz}$, 4H), $6.80(\mathrm{t}, J=7.5 \mathrm{~Hz}, 2 \mathrm{H}), 4.23(\mathrm{~s}, 4 \mathrm{H}), 3.69(\mathrm{~s}, 4 \mathrm{H}) .{ }^{13} \mathrm{C} \mathrm{NMR}\left(300 \mathrm{MHz}, \mathrm{CDCl}_{3}\right)$ : $190.6,154.6,148.2,131.1,129.5,128.9,128.4,127.8,127.3$. Melting point $>230^{\circ} \mathrm{C}$. HRMS $\left((\mathrm{M}-\mathrm{H})^{-1} \mathrm{~m} / z\right)$ : Calculated for $\mathrm{C}_{30} \mathrm{H}_{23} \mathrm{O}_{6}{ }^{-}$, 479.15001, Found 479.14987. FT-IR $\left(\mathrm{cm}^{-1}\right): 3179(\mathrm{br}), 1679(\mathrm{~m}), 1596(\mathrm{~m}), 1454(\mathrm{~m}), 1280(\mathrm{~m}), 752(\mathrm{~m})$.

\section{1,3-dinitro-calix[4]arene (Compound 15)}

Compound $12(0.82 \mathrm{~g}, 1.13 \mathrm{mmol})$ was added to methanol $(50 \mathrm{~mL})$. Sodium hydroxide $(0.68,17.1 \mathrm{mmol})$ was added to the suspension, which was then heated at $70^{\circ} \mathrm{C}$ for 4 
hours. The reaction was quenched with hydrochloric acid $(1 \mathrm{M})$ and the precipitate was collected by vacuum filtration. The crude product was triturated in hot hexanes to remove the benzoic acid, yielding compound 15 as a dark brown/purple solid $(0.529 \mathrm{~g}, 90 \%) .{ }^{1} \mathrm{H}$ NMR (300 MHz, $\left.\left(\mathrm{CD}_{3}\right)_{2} \mathrm{SO}\right): \delta 8.02(\mathrm{~s}, 4 \mathrm{H}), 7.12(\mathrm{~d}, J=7.5 \mathrm{~Hz}, 4 \mathrm{H}), 6.63(\mathrm{t}, J=7.5$, 2H), 3.93 (s, 8H). ${ }^{13} \mathrm{C}$ NMR (300 MHz, $\left.\mathrm{D}_{2} \mathrm{O}\right): 161.8,151.2,138.0,130.3,128.61,128.55$, 124.0, 120.4, 30.8. Melting point $>230^{\circ} \mathrm{C}$. HR-MS $\left((\mathrm{M}-\mathrm{H})^{-1} \mathrm{~m} / z\right)$ : Calculated for $\mathrm{C}_{28} \mathrm{H}_{21} \mathrm{~N}_{2} \mathrm{O}_{8}{ }^{-}, 513.13034$, Found 513.12995. FT-IR ( $\left.\mathrm{cm}^{-1}\right): 3091$ (br), 1515 (m), 1340 (s), $764(\mathrm{~m})$.

\section{1,3-diformyl-2,4-disulfocalix[4]arene (Compound 4)}

Compound 14 (0.47g, $0.97 \mathrm{mmol})$ was added to DCM (20 mL). While stirring, sulfuric acid $(0.764 \mathrm{~g}, 7.79 \mathrm{mmol})$ was added. The solution was heated to $40^{\circ} \mathrm{C}$ overnight. The DCM was decanted and a minimum amount of ethyl acetate was added to the precipitate, after which a slurry was formed by sonication. The crude product was suspended by pouring the slurry into a $50 \mathrm{~mL}$ Falcon tube containing ice-cold ether $(35 \mathrm{~mL})$. The suspension was centrifuged and the supernatant was discarded. The pellet was air dried and purified by high pressure liquid chromatography on a Shimadzu Prominence HPLC system over a $9.4 \mathrm{~mm}$ x $250 \mathrm{~mm}$ semi-preparative Agilent Eclipse XDB-C18 $5 \mu \mathrm{m}$ with UV detection at $280 \mathrm{~nm}$. A gradient ran from $90 \% \mathrm{H}_{2} \mathrm{O}(+0.1 \% \mathrm{TFA}) / 10 \% \mathrm{CH}_{3} \mathrm{CN}$ $\left(+0.1 \%\right.$ TFA) to $85 \% \mathrm{H}_{2} \mathrm{O}(+0.1 \%$ TFA $) / 15 \% \mathrm{CH}_{3} \mathrm{CN}(+0.1 \%$ TFA $)$ over 7 minutes, to $50 \% \mathrm{H}_{2} \mathrm{O}(+0.1 \%$ TFA $) / 50 \% \mathrm{CH}_{3} \mathrm{CN}(+0.1 \%$ TFA $)$ over 13 minutes. The fractions were collected and lyophilized, yielding compound 4 as a light brown solid $(0.168 \mathrm{~g}, 27 \%) .{ }^{1} \mathrm{H}$ NMR (300 MHz, D $2 \mathrm{O}): \delta 9.12(\mathrm{~s}, 2 \mathrm{H}), 7.58(\mathrm{~s}, 4 \mathrm{H}), 7.41(\mathrm{~s}, 4 \mathrm{H}), 3.78(\mathrm{~s}, 8 \mathrm{H}) .{ }^{13} \mathrm{C}$ NMR $\left(300 \mathrm{MHz}, \mathrm{D}_{2} \mathrm{O}\right): 193.8,155.2,151.1,136.2,131.5,129.7,128.2,128.0,126.7,30.2$. Melting point $>230^{\circ} \mathrm{C}$. HR-MS $\left((\mathrm{M}-\mathrm{H})^{-1} \mathrm{~m} / z\right)$ : Calculated for $\mathrm{C}_{30} \mathrm{H}_{21} \mathrm{O}_{12} \mathrm{~S}_{2}{ }^{-}, 639.06364$, 
Found 639.06473. FT-IR (cm $\left.{ }^{-1}\right): 3180$ (br), 1670 (m), 1593 (m), 1133 (m), 1036 (m).

\section{1,3-dinitro-2,4-disulfocalix[4]arene (Compound 5)}

Compound $15(0.53 \mathrm{~g}, 1.02 \mathrm{mmol})$ was added to DCM (20 mL). While stirring, sulfuric acid $(0.804 \mathrm{~g}, 8.19 \mathrm{mmol})$ was added and the solution was heated to $40^{\circ} \mathrm{C}$ overnight. The DCM was decanted and a minimum amount of ethyl acetate was added to the precipitate, after which a slurry was formed by sonication. The crude product was suspended by pouring the slurry into a $50 \mathrm{~mL}$ Falcon tube containing ice-cold ether $(35 \mathrm{~mL})$. The suspension was centrifuged and the supernatant was discarded. The pellet was air dried and purified by high pressure liquid chromatography using the same method as reported for compound $\mathbf{4}$. The fractions were collected and lyophilized, yielding compound $\mathbf{5}$ as a light brown solid (0.145 g, 21\%). ${ }^{1} \mathrm{H}$ NMR (300 MHz, $\left.\mathrm{D}_{2} \mathrm{O}\right): \delta 7.87$ (s, 4H), $7.55(\mathrm{~s}, 4 \mathrm{H})$, $3.85(\mathrm{~s}, 8 \mathrm{H}) .{ }^{13} \mathrm{C}$ NMR $\left(300 \mathrm{MHz}, \mathrm{D}_{2} \mathrm{O}\right): 156.1,151.3,140.5,136.0,128.2,127.5,126.8$, 124.9, 30.3. Melting point $>230^{\circ} \mathrm{C}$. HR-MS $\left((\mathrm{M}-2 \mathrm{H})^{-2} \mathrm{~m} / \mathrm{z}\right)$ : Calculated for $\mathrm{C}_{28} \mathrm{H}_{20} \mathrm{~N}_{2} \mathrm{O}_{14} \mathrm{~S}_{2}{ }^{-2}$, 336.01834, Found 336.01858. FT-IR (cm ${ }^{-1}$ ): 3186 (br), 1518 (w), 1339 (m), $1110(\mathrm{~m}), 1036(\mathrm{~m})$.

\section{3,4-dibenzoylcalix[4]arene (Compound 9)}

Compound 8 [21] (4.0 g, $6.32 \mathrm{mmol})$ and cesium carbonate (4.12 g, $12.6 \mathrm{mmol})$ were added to a dry round bottom flask. The system was evacuated and flushed three times with nitrogen. Dry acetonitrile $(150 \mathrm{~mL})$ was added via cannula under a nitrogen atmosphere. The reaction was stirred at $55^{\circ} \mathrm{C}$ for 1.5 hours. The solvent was removed in vacuo and residue was re-dissolved in a minimum volume of DCM. The organic layer was washed three times with $1 \mathrm{M} \mathrm{HCl}$ and once with brine after which it was dried over magnesium sulfate. The DCM was concentrated under reduced pressure and the product was precipitated in ice-cold ether. The precipitate was collected by vacuum filtration, 
yielding compound 9 as a yellow solid (3.6 g, 90\%) that was carried forward without further purification.

\section{1,2-diformyl-3,4-dibezoylcalix[4]arene (Compound 11)}

Compound 9 (1.0 g, $1.58 \mathrm{mmol})$ and HMTA (1.99 g, $14.2 \mathrm{mmol})$ were added to TFA (20 $\mathrm{mL}$ ) and heated to $70^{\circ} \mathrm{C}$ overnight. The reaction was quenched with water and the precipitate collected by vacuum filtration, yielding compound $\mathbf{1 1}$ as a pale yellow solid $(0.936 \mathrm{~g}, 86 \%)$ that was carried forward without further purification.

\section{1,2-dinitro-3,4-dibezoylcalix[4]arene (Compound 13 )}

Compound 9 ( $1.0 \mathrm{~g}, 1.58 \mathrm{mmol})$ and potassium nitrate $(0.399 \mathrm{~g}, 3.95 \mathrm{mmol})$ were added to a dry round bottom flask. The system was evacuated and flushed three times with nitrogen. Dry acetonitrile $(100 \mathrm{~mL})$ was added via cannula. Boron trifluoride diethyl etherate $(0.561 \mathrm{~g}, 3.95 \mathrm{mmol})$ was added via syringe and the reaction was stirred under nitrogen atmosphere at room temperature for $48 \mathrm{~h}$. The reaction was quenched with hydrochloric acid (1 M) and the precipitate was collected by vacuum filtration, yielding compound 13 as a yellow solid $(0.742 \mathrm{~g}, 65 \%)$ that was carried forward without further purification.

\section{1,2-diformylcalix [4]arene (Compound 16)}

Compound 11 (0.94 g, $1.36 \mathrm{mmol})$ was added to methanol $(50 \mathrm{~mL})$. Sodium hydroxide $(0.815,20.4 \mathrm{mmol})$ was added to the suspension, which was heated at reflux at $70^{\circ} \mathrm{C}$ for 4 hours. The reaction was quenched with hydrochloric acid (1 M) and the precipitate was collected by vacuum filtration. The crude product was triturated in hot hexanes to remove the benzoic acid, yielding compound 16 as a dark brown/purple solid $(0.411 \mathrm{~g}, 63 \%) .{ }^{1} \mathrm{H}$ NMR (500 MHz, $\left.\mathrm{CDCl}_{3}\right): \delta 10.16(\mathrm{~s}, 4 \mathrm{H}), 9.77(\mathrm{~s}, 2 \mathrm{H}), 7.64(\mathrm{~s}, 4 \mathrm{H}), 7.10(\mathrm{~d}, J=7.5 \mathrm{~Hz}$ 
2H), $7.08(\mathrm{~d}, J=7.7 \mathrm{~Hz}, 2 \mathrm{H}), 6.76(\mathrm{t}, J=7.7 \mathrm{~Hz}, 2 \mathrm{H}), 4.28(\mathrm{~s}, 4 \mathrm{H}), 3.66(\mathrm{~s}, 4 \mathrm{H}) .{ }^{13} \mathrm{C}$ $\operatorname{NMR}\left(500 \mathrm{MHz}, \mathrm{CDCl}_{3}\right): \delta$ 190.4, 154.4, 148.3, 131.4, 131.3, 131.0, 130.0, 129.5, 129.4, 129.2, 128.2, 128.1, 127.0, 122.7, 31.5. Melting point $>230^{\circ} \mathrm{C}$. HR-MS $\left((\mathrm{M}-\mathrm{H})^{-1} \mathrm{~m} / \mathrm{z}\right)$ : Calculated for $\mathrm{C}_{30} \mathrm{H}_{23} \mathrm{O}_{6}{ }^{-}$, 479.15001, Found 479.15009. FT-IR $\left(\mathrm{cm}^{-1}\right): 3189$ (br), 1678 (m), $1596(\mathrm{~m}), 1285(\mathrm{~m}), 1128(\mathrm{~m}), 756(\mathrm{~m})$.

\section{1,2-dinitrocalix[4]arene (Compound 17)}

Compound 13 (0.74 g, $1.03 \mathrm{mmol})$ was added to methanol $(50 \mathrm{~mL})$. Sodium hydroxide $(0.616,15.4 \mathrm{mmol})$ was added to the suspension. The solution was heated at reflux at $70^{\circ} \mathrm{C}$ for 4 hours. The reaction was quenched with hydrochloric acid (1 M) and the precipitate was collected by vacuum filtration. The crude product was triturated in hot hexanes to remove the benzoic acid, yielding compound $\mathbf{1 7}$ as a dark brown/purple solid $(0.465 \mathrm{~g}, 88 \%)$ that was carried forward without further purification.

\section{1,2-diformyl-3,4-disulfocalix[4]arene (Compound 6)}

Compound $16(0.30 \mathrm{~g}, 0.63 \mathrm{mmol})$ was added to DCM $(20 \mathrm{~mL})$. While stirring, sulfuric acid $(0.491 \mathrm{~g}, 5.00 \mathrm{mmol})$ was added. The solution was heated to $40^{\circ} \mathrm{C}$ overnight. The DCM was decanted and a minimum amount of ethyl acetate was added to the precipitated after which a slurry was formed by sonication. The crude product was suspended by pouring the slurry into a $50 \mathrm{~mL}$ Falcon tube with ice-cold ether $(35 \mathrm{~mL})$. The suspension was centrifuged and the supernatant was discarded. The pellet was air dried and purified by high pressure liquid chromatography The pellet was air dried and purified by high pressure liquid chromatography on a Shimadzu Prominence HPLC system over a $9.4 \mathrm{~mm}$ x $250 \mathrm{~mm}$ semi-preparative Agilent Eclipse XDB-C18 $5 \mu \mathrm{m}$ with UV detection at 280 nm. A gradient ran from $90 \% \mathrm{H}_{2} \mathrm{O}(+0.1 \%$ TFA $) / 10 \% \mathrm{CH}_{3} \mathrm{CN}\left(+0.1 \%\right.$ TFA) to $75 \% \mathrm{H}_{2} \mathrm{O}$ $(+0.1 \%$ TFA $) / 25 \% \mathrm{CH}_{3} \mathrm{CN}\left(+0.1 \%\right.$ TFA) over 7 minutes, to $50 \% \mathrm{H}_{2} \mathrm{O}(+0.1 \% \mathrm{TFA}) / 50 \%$ 
$\mathrm{CH}_{3} \mathrm{CN}(+0.1 \%$ TFA) over 13 minutes. The fractions were collected and lyophilized, yielding compound 6 as a light brown solid $(0.107 \mathrm{~g}, 17 \%) .{ }^{1} \mathrm{H}$ NMR $\left(500 \mathrm{MHz}, \mathrm{D}_{2} \mathrm{O}\right)$ : $\delta 9.38(\mathrm{~s}, 2 \mathrm{H}), 7.62(\mathrm{~s}, 2 \mathrm{H}), 7.58(\mathrm{~s}, 2 \mathrm{H}), 7.56(\mathrm{~s}, 4 \mathrm{H}), 4.02(\mathrm{~s}, 2 \mathrm{H}), 3.97(\mathrm{~s}, 4 \mathrm{H}), 3.78(\mathrm{~s}$, 2H). ${ }^{13} \mathrm{C}$ NMR $\left(500 \mathrm{MHz}, \mathrm{D}_{2} \mathrm{O}\right) \delta 193.74,154.96,151.11,136.24,132.19,131.10$, $129.95,128.30,128.10,128.05,127.90,126.64,126.59,30.65,30.42,29.93$. Melting point $>230^{\circ} \mathrm{C}$. HR-MS $\left((\mathrm{M}-\mathrm{H})^{-1} \mathrm{~m} / z\right)$ : Calculated for $\mathrm{C}_{30} \mathrm{H}_{21} \mathrm{O}_{12} \mathrm{~S}_{2}^{-}, 639.06364$, Found 639.06443. FT-IR (cm $\left.{ }^{-1}\right): 3185$ (br), 1674 (m), 1234 (s), 1036 (s), 623 (s).

\section{1,2-dinitro-3,4-disulfocalix [4]arene (Compound 7)}

Compound $17(0.47 \mathrm{~g}, 0.90 \mathrm{mmol})$ was added to DCM $(20 \mathrm{~mL})$. While stirring, sulfuric acid $(0.709 \mathrm{~g}, 7.23 \mathrm{mmol})$ was added and the solution was heated to $40^{\circ} \mathrm{C}$ overnight. The DCM was decanted and a minimum amount of ethyl acetate was added to the precipitate after which a slurry was formed by sonication. The crude product was suspended by pouring the slurry into a $50 \mathrm{~mL}$ Falcon tube containing ice-cold ether $(35 \mathrm{~mL})$. The suspension was centrifuged and the supernatant was discarded. The pellet was air dried and purified by high pressure liquid chromatography as was reported for compound $\mathbf{6}$. The fractions were collected and lyophilized, yielding compound 7 as a light brown solid (0.093 g, 17\%). ${ }^{1} \mathrm{H}$ NMR (300 MHz, D2O): $\delta 8.00$ (s, 2H), 7.91 (s, 2H), 7.53 (s, 4H), 3.97 (s, 6H), $3.73(\mathrm{~s}, 2 \mathrm{H}) .{ }^{13} \mathrm{C}$ NMR (500 MHz, $\left.\mathrm{D}_{2} \mathrm{O}\right) \delta 162.71,153.82,138.39,134.68$, $130.66,130.46,129.72,129.64,126.08,125.99,125.11,125.05,31.89,31.29,30.90$. Melting point $>230^{\circ} \mathrm{C}$. HR-MS $\left((\mathrm{M}-2 \mathrm{H})^{-2} \mathrm{~m} / \mathrm{z}\right)$ : Calculated for $\mathrm{C}_{28} \mathrm{H}_{20} \mathrm{~N}_{2} \mathrm{O}_{14} \mathrm{~S}_{2}{ }^{-2}$, 336.01834. Found 336.01862. FT-IR ( $\left.\mathrm{cm}^{-1}\right)$ : 3211 (br), 1679 (m), $1446(\mathrm{w}), 1340$ (w) 1187 (s), 1135 (s) 1048 (m), 724 (m). 


\section{Results and Discussion}

\section{Synthesis}

We synthesized a small set of structurally related sulfonatocalix[4]arenes with regioselective introduction of different functional groups. We adapted an approach that uses regioselective protection of lower-rim phenols,[22] followed by sequences of electrophilic aromatic substitutions at the upper rim, deprotection of the lower rim, and ultimately sulfonation of the remaining upper-rim sites (Figure 1). The commercially available $p$-sulfonatocalix[4]arene (compound $\mathbf{1}, \mathrm{sCx} 4$ ) is used in all studies for comparison. The targets for synthesis included mono-substituted sulfonatocalix[4]arenes (nitro-substituted compound $\mathbf{2}$ and formyl-substituted compound $\mathbf{3}$ ), which come from a tribenzoylated intermediate $[22,23]$ and were previously reported, $[6,7,24]$ as well as novel di-substituted calix[4]arenes (1,3-diformyl compound 4, 1,3-dinitro compound $\mathbf{5}$, 1,2-diformyl compound 6, 1,2-dinitro compound 7).

The synthesis of the disubstituted hosts proceeds efficiently by using different dibenzoyl-protected calixarenes as key intermediates. The 1,3-dibenzoyl protected compound 8 [21] can be carried forward to make 1,3-disubstituted hosts (see below). We optimized a previously reported procedure [25] for benzoyl rearrangement of compound $\mathbf{8}$ to yield 1,2-dibenzoylated compound $\mathbf{9}$. From either $\mathbf{8}$ or $\mathbf{9}$, the nitro- or formyl-groups are then introduced onto each unsubstituted phenol ring, with the benzoyl protection groups on the lower rim offering remote protection by deactivating rings toward electrophilic aromatic substitutions. The formylated products $\mathbf{1 0}$ and $\mathbf{1 1}$ were prepared using a Duff formylation with hexamethylenetetramine (HMTA) and trifluoroacetic acid. For the nitration we used potassium nitrate and boron trifluoride diethyl etherate[26], to acquire compounds $\mathbf{1 2}$ and $\mathbf{1 3}$. Each of these conditions were selected to substitute the calix[4]arenes under mild conditions to minimize over-modification. The regioselectively 
dinitrated and diformylated products are obtained in $65-86 \%$ isolated yields in spite of the fact that each starting material has 27 aromatic C-H's that are potential sites for electrophilic aromatic substitution. The lower rim was then deprotected by basic hydrolysis, yielding compounds 14-17, some of which were carried forward without purification (see Supporting Information). The de-protected calix[4]arenes 14-17 were sulfonated under mild conditions using eight equivalents of sulfuric acid in dichloromethane to provide novel host compounds 4-7.

\section{Binding studies}

The binding constants were determined between a set of seven calix[4]arene hosts (1-7), and the guests nicotine, nornicotine, and cotinine. The binding constants were initially determined via indicator displacement assays (IDAs) based on an IDA previously reported for $\mathrm{sCx}$ 4.[27] Each calixarene was first titrated directly into lucigenin (LCG) in order to determine the calixarene-dye $\mathrm{K}_{\mathrm{d}}$ values, which range from 1.37-2.11 $\mu \mathrm{M}$ (Figure 2a). During the ensuing competitive titrations, the indicator LCG was displaced from the calix[4]arene binding pocket by added guests and increased its fluorescence emission.[27, 28] The fluorescence was measured and plotted against the concentration of guest, and the resulting curve was fitted to determine the binding constant for each host-guest pair (Figure $2 b-d)$.

The studied guests display distinct differences in their binding constants. Nicotine and nornicotine display medium $\left(\mathrm{K}_{\mathrm{d}} 200-1000 \mu \mathrm{M}\right)$ to strong binding $\left(\mathrm{K}_{\mathrm{d}}<200 \mu \mathrm{M}\right)$, whereas cotinine shows very weak to no binding $\left(\mathrm{K}_{\mathrm{d}}>1000 \mu \mathrm{M}\right)$ to any host studied. Rather than the amines present in nicotine and nornicotine, cotinine contains an amide bond. This renders cotinine uncharged at neutral $\mathrm{pH}$, and the lack of cationic charge weakens binding significantly. Overall, nicotine binds the hosts in general stronger than 
its slightly less hydrophobic metabolite nornicotine, but they are in a similar binding range (Table 1). The lack of measurable binding for neutral cotinine shows that a cationic group on the guest is absolutely required for binding. Based on the IDA data, nicotine was selected for further NMR-based binding and structural studies.

The binding strengths and motifs of nicotine with the library of calix[4]arene hosts were further studied using NMR titrations. [29, 30] Titration data were analysed using the open source website: http://supramolecular.org in order to determine binding constants (see Supporting Information). The binding constants (Table 2) are similar to those determined by IDA and reveal similar trends among related family members in most cases, except for compound $\mathbf{2}$. The IDA data showed a stronger binding for compound $\mathbf{2}$ than do the NMR data. The NMR data is a direct measurement, where the data arises from a direct observation of many changing chemical shifts, while the IDA arises from an indirect measurement from two competing equilibria. Where the two methods disagree, we take the NMR titration as the more reliable source for the binding constants.

In addition to $K_{d}$ values, the NMR curve fitting provides structural insight by providing maximum binding-induced chemical shift $\left(\Delta \delta_{\max }\right)$ values. The nicotine protons involved in complexation with the interior of the host become shielded, causing chemical shifts to move upfield. The difference in chemical shift upon binding tells us how deep each proton is within the host's pocket, which we can interpret to determine how the guest is positioned inside of each host.[31, 32]

There are three possible binding motifs for calix[4]arene host-guest complexes of this type.[33, 34] In binding motif $I$, the biggest chemical shift is observed for the $N$ methyl, because the pyrrolidine ring is deeply bound in the pocket. For binding motif $I$, the biggest chemical shift is observed for pyridine protons due to the pyridine deeply bound in the pocket. In binding motif $I I I$, a similar (but relatively small) maximum 
chemical shift is observed for all protons as the protons associate with the upper rim but do not enter the binding pocket, see Figure 3. This kind of non-insertion binding mode is less common for calixarenes, but has been seen, for example, when lysine binds to $\mathrm{sCx} 4 .[33,35]$

The formyl-substituted hosts $\mathbf{2}, \mathbf{4}$, and $\mathbf{6}$ bind nicotine via binding motif $I$. The biggest chemical shift is observed for the pyrrolidine protons, as they bind the deepest into the formylated binding pocket. This is consistent with the relative values of dissociation constants. Compound $\mathbf{2}$ has three anionic charges at the upper rim. When the pyrrolidine binds deeply in the pocket these charged groups are adjacent to the electronpoor pyridine heterocycle, forming less favourable host-guest contacts compared to compounds 3 and 4, which each have two anionic charges at the upper rim. This is reflected in the weaker binding of nicotine by 2 relative to 3 and 4 (Table 2).

The nitro-substituted hosts bind nicotine via binding motif $I I$. Here, the biggest chemical shift is observed for the pyridine protons, and again we see trends in the binding constants that are consistent with this host-guest structure. When the pyridine is deep in the pocket, the positively charged pyrrolidine interacts favourably with the anionic charges of the hosts. Compound $\mathbf{3}$ has three anionic charges at the upper rim and shows the strongest binding to nicotine, whereas compounds $\mathbf{5}$ and $\mathbf{7}$ have two anionic charges and display weaker binding than compound 3 . The close proximity of the anionic charges of compound 7 are favourable for binding compared to when the charges are located further apart in compound 5. Overall, the control, compound $\mathbf{1}\left(\mathrm{K}_{\mathrm{d}}=100 \mu \mathrm{M}\right)$, shows the strongest binding to nicotine followed by compound $3\left(\mathrm{~K}_{d}=150 \mu \mathrm{M}\right)$ from the set of new hosts.

These studies show how the number and positions of charged sulfonates can modulate sulfonatocalix[4]arene host-guest complexation, and also how substituents can 
cause structural differences in guest binding that are not immediately obvious from the binding constants themselves. A bigger chemical shift tells us how deeply a proton is buried in the binding pocket, but does not directly indicate that stronger binding is occurring. Even though the biggest maximum chemical shift perturbation $(2.40 \mathrm{ppm})$ is observed for compound $\mathbf{5}$, it is one of the weaker binding hosts. In some cases a very small chemical shift can arise from strong complexation. This is most clearly observed for compound $\mathbf{1}$, where all the chemical shifts are smaller than $1 \mathrm{ppm}$. The chemical shift profile for host $\mathbf{1}$ is hard to interpret definitively, and suggests that the guest is bound by some mixture of modes $I, I I$, and/or $I I I$.

\section{Conclusions}

In summary, we have synthesised a set of novel calix[4]arene hosts and studied their binding to nicotine, nornicotine and cotinine. The parent compound $\mathbf{1}$ binds nicotine and nornicotine the strongest, while other calix[4]arenes show different patterns of binding selectivity depending on the identity and position of upper-rim substitutions. From among the guests, nicotine forms the strongest host-guest complexes because it is cationic, unlike cotinine, and it is slightly more hydrophobic than nornicotine. From among the substituted host compounds $\mathbf{2 - 7}$, compound $\mathbf{3}$ shows the strongest binding. In the future, this fundamental knowledge of binding strengths and motifs can be applied further to a broad range of guest molecules, and the functional groups we've installed offer easy routes to further elaboration of the regioselectivity functionalized host scaffolds.

\section{Acknowledgments}

We thank Allison Selinger for helpful discussions on the data analysis for indicator displacement assays. 


\section{Declaration of interest statement}

No potential conflict of interest was reported by the authors.

Funding details. This research was supported by NSERC Discovery Grant RGPIN2019-04806, Deutsche Forschungsgemeinschaft (BA1624/15-1), and a Canada Research Chair awarded to FH.

\section{Supplemental material}

Characterization data for all new compounds, detailed protocols for curve fitting, exemplary fluorescence and NMR titration data for all binding partners.

\section{References}

1. Gutsche CD. Calixarenes. Accounts Chem Res. 1983;16(5):161-170. PubMed PMID: WOS:A1983QU83200004; English.

2. Harvey PD. Wide-rim and outer-face functionalizations of calix[4]arene. Coordin Chem Rev. 2002 Nov;233:289-309. PubMed PMID: WOS:000178841400017; English.

3. Pinkin NK, Power AN, Waters ML. Late stage modification of receptors identified from dynamic combinatorial libraries. Org Biomol Chem. 2015;13(44):10939-10945. PubMed PMID: WOS:000364077400019; English.

4. Gilberg L, Khan MSA, Enderesova M, et al. Cucurbiturils Substituted on the Methylene Bridge. Org Lett. 2014 May 2;16(9):2446-2449. PubMed PMID: WOS:000335491000038; English.

5. Vinciguerra B, Cao LP, Cannon JR, et al. Synthesis and Self-Assembly Processes of Monofunctionalized Cucurbit[7]uril. J Am Chem Soc. 2012 Aug 8;134(31):13133-13140. PubMed PMID: WOS:000307210900038; English.

6. Daze KD, Ma MCF, Pineux F, et al. Synthesis of New Trisulfonated Calix[4]arenes Functionalized at the Upper Rim, and Their Complexation with the Trimethyllysine Epigenetic Mark. Org Lett. 2012 Mar 16;14(6):1512-1515. PubMed PMID: WOS:000301516000039; English.

7. Tabet S, Douglas SF, Daze KD, et al. Synthetic trimethyllysine receptors that bind histone 3, trimethyllysine 27 (H3K27me3) and disrupt its interaction with the epigenetic reader protein CBX7. Bioorgan Med Chem. 2013 Nov 15;21(22):7004-7010. PubMed PMID: WOS:000325759800016; English.

8. Ali M, Daze KD, Strongin DE, et al. Molecular Insights into Inhibition of the Methylated Histone-Plant Homeodomain Complexes by Calixarenes. J Biol 
Chem. 2015 Sep;290(38):22919-22930. PubMed PMID:

WOS:000361685500005; English.

9. Allen HF, Daze KD, Shimbo T, et al. Inhibition of histone binding by supramolecular hosts. Biochem J. 2014 May 1;459(3):505-12. doi: 10.1042/BJ20140145. PubMed PMID: 24576085; PubMed Central PMCID: PMCPMC4454452.

10. Wang Z. Encyclopedia of Physical Organic Chemistry. John Wiley \& Sons, Inc; 2016. (Daze KD, Hof F, editors. Molecular interaction and recognition).

11. Perret F, Lazar AN, Coleman AW. Biochemistry of the para-sulfonatocalix[n]arenes. Chem Commun. 2006 (23):2425-2438. PubMed PMID: WOS:000238101100001; English.

12. Coleman AW, Jebors S, Cecillon S, et al. Toxicity and biodistribution of parasulfonato-calix[4] arene in mice. New J Chem. 2008;32(5):780-782. PubMed PMID: WOS:000255743600005; English.

13. Nimse SB, Kim T. Biological applications of functionalized calixarenes. Chem Soc Rev. 2013;42(1):366-386. PubMed PMID: WOS:000311968700020; English.

14. Kanamathareddy S, Gutsche CD. Calixarenes - Selective Functionalization and Bridge Building. J Org Chem. 1995 Sep 22;60(19):6070-6075. PubMed PMID: WOS:A1995RW87800017; English.

15. Kanamathareddy S, Gutsche CD. Selective upper rim functionalization and lower rim bridge building with calix[4]arenes and calix[6]arenes. J Org Chem. 1996 Apr 5;61(7):2511-2516. PubMed PMID: WOS:A1996UD65300040; English.

16. Shinkai S, Araki K, Manabe O. Does the Calixarene Cavity Recognize the Size of Guest Molecules - on the Hole-Size Selectivity in Water-Soluble Calixarenes. J Chem Soc Chem Comm. 1988 Feb 1(3):187-189. PubMed PMID: WOS:A1988M078100022; English.

17. Zhou YY, Yu HP, Zhang L, et al. A new spectrofluorometric method for the determination of nicotine base on the inclusion interaction of methylene blue and cucurbit[7]uril. Microchim Acta. 2009 Jan;164(1-2):63-68. PubMed PMID: WOS:000262438900009; English.

18. Minami T, Esipenko NA, Zhang B, et al. Supramolecular Sensor for CancerAssociated Nitrosamines. J Am Chem Soc. 2012 Dec 12;134(49):20021-20024. PubMed PMID: WOS:000312351000018; English.

19. Berglund J, Cedergren L, Andersson SB. Determination of the stability constant for the inclusion complex between beta-cyclodextrin and nicotine using capillary electrophoresis. Int J Pharm. 1997 Oct 24;156(2):195-200. PubMed PMID: WOS:A1997XZ73900008; English.

20. Benowitz NL. Clinical pharmacology of nicotine: Implications for understanding, preventing, and treating tobacco addiction. Clin Pharmacol Ther. 2008 Apr;83(4):531-541. PubMed PMID: WOS:000254330000013; English.

21. Vanloon JD, Arduini A, Coppi L, et al. Selective Functionalization of Calix[4]Arenes at the Upper Rim. J Org Chem. 1990 Oct 12;55(21):5639-5646. PubMed PMID: WOS:A1990ED04500024; English.

22. Gutsche CD, Lin LG. Calixarenes .12. The Synthesis of Functionalized Calixarenes. Tetrahedron. 1986;42(6):1633-1640. PubMed PMID: WOS:A1986A952000013; English. 
23. Berthalon S, deVains JBR, Lamartine R. Selective mono-dealkylation of tetra-ptert-butyl-calix[4]arene at the upper rim. Synthetic Commun. 1996;26(16):31033108. PubMed PMID: WOS:A1996UT17900017; English.

24. Beatty MA, Borges-Gonzalez J, Sinclair NJ, et al. Analyte-Driven Disassembly and Turn-On Fluorescent Sensing in Competitive Biological Media. J Am Chem Soc. 2018 Mar 14;140(10):3500-3504. PubMed PMID: WOS:000427910700005; English.

25. Lynch JA, Mestayer JJ, Blanda MT. Efficient Syntheses of Calix[4]arenes in the 1,2-AlternateConformation Via Intramolecular Benzoate Ester Migrations. Journal of Supramolecular Chemistry. 2001;1(3):139-145. doi: https://doi.org/10.1016/S1472-7862(02)00005-9.

26. Olah GA, Narang SC, Olah JA, et al. Recent Aspects of Nitration - New Preparative Methods and Mechanistic Studies (a Review). P Natl Acad Sci USA. 1982;79(14):4487-4494. PubMed PMID: WOS:A1982NY24400002; English.

27. Guo DS, Uzunova VD, Su X, et al. Operational calixarene-based fluorescent sensing systems for choline and acetylcholine and their application to enzymatic reactions. Chem Sci. 2011;2(9):1722-1734. PubMed PMID: WOS:000293693700012; English.

28. Dsouza RN, Pischel U, Nau WM. Fluorescent Dyes and Their Supramolecular Host/Guest Complexes with Macrocycles in Aqueous Solution. Chem Rev. 2011 Dec;111(12):7941-7980. PubMed PMID: WOS:000297946600011; English.

29. Thordarson P. Determining association constants from titration experiments in supramolecular chemistry (vol 40, pg 1305, 2011). Chem Soc Rev. 2011;40(12):5922-5923. PubMed PMID: WOS:000296986000025; English.

30. Hibbert DB, Thordarson P. The death of the Job plot, transparency, open science and online tools, uncertainty estimation methods and other developments in supramolecular chemistry data analysis. Chem Commun. 2016;52(87):1279212805. PubMed PMID: WOS:000387025600001; English.

31. Laughrey ZR, Gibb CLD, Senechal T, et al. Guest binding and orientation within open nanoscale hosts. Chem-Eur J. 2003 Jan 3;9(1):130-139. PubMed PMID: WOS:000180368600011; English.

32. Twum K, Rautiainen JM, Yu SL, et al. Host-Guest Interactions of Sodiumsulfonatomethyleneresorcinarene and Quaternary Ammonium Halides: An Experimental-Computational Analysis of the Guest Inclusion Properties. Cryst Growth Des. 2020 Apr 1;20(4):2367-2376. PubMed PMID: WOS:000526390000025; English.

33. Beshara CS, Jones CE, Daze KD, et al. A Simple Calixarene Recognizes Posttranslationally Methylated Lysine. Chembiochem. 2010 Jan 4;11(1):63-66. PubMed PMID: WOS:000273712200007; English.

34. Guo DS, Wang K, Liu Y. Selective binding behaviors of p-sulfonatocalixarenes in aqueous solution. J Incl Phenom Macro. 2008 Oct;62(1-2):1-21. PubMed PMID: WOS:000258902200001; English.

35. Selkti M, Coleman AW, Nicolis I, et al. The first example of a substrate spanning the calix[4]arene bilayer: the solid state complex of psulfonatocalix[4]arene with L-lysine. Chem Commun. 2000 (2):161-162. PubMed PMID: WOS:000084957700026; English. 
Table 1: $K_{d}$ values determined by IDA for each host with Nicotine, Nornicotine and Cotinine. $\left.{ }^{\mathrm{a}, \mathrm{b}}\right)$

\begin{tabular}{lll|l}
\hline & \multicolumn{1}{c}{ Nicotine } & \multicolumn{1}{l}{ Nornicotine } & \multicolumn{1}{c}{ Cotinine } \\
& $\mathrm{K}_{\mathrm{d}}(\mu \mathrm{M})$ & \multicolumn{1}{c}{$\mathrm{K}_{\mathrm{d}}(\mu \mathrm{M})$} & \multicolumn{1}{c}{$\mathrm{K}_{\mathrm{d}}(\mu \mathrm{M})$} \\
\hline Compound 1 (sCx4) & $140 \pm 30$ & $290 \pm 130$ & $>1500$ \\
Compound 2 (1-formyl) & $80 \pm 20$ & $190 \pm 50$ & $>1500$ \\
Compound 6 (1,2-formyl) & $290 \pm 60$ & $690 \pm 170$ & $>1500$ \\
Compound 4 (1,3-formyl) & $120 \pm 30$ & $750 \pm 100$ & $>1500$ \\
Compound 3 (1-nitro) & $170 \pm 40$ & $500 \pm 110$ & $>1500$ \\
Compound 7 (1,2-nitro) & $640 \pm 120$ & $960 \pm 150$ & $>1500$ \\
Compound 5 (1,3-nitro) & $730 \pm 140$ & $1200 \pm 260$ & $>1500$ \\
\hline
\end{tabular}

a) $0.01 \mathrm{M}$ phosphate buffer $\mathrm{pH} 7.4$, see the supporting information for titration curves and experimental details.

b) the IDAs for nicotine and nornicotine are done in duplicates of triplicates, the IDAs for cotinine are done in duplicates of duplicates. 
Table 2: NMR summery, maximum chemical shift of nicotine protons upon binding with host library and $\mathrm{Kd}$ values

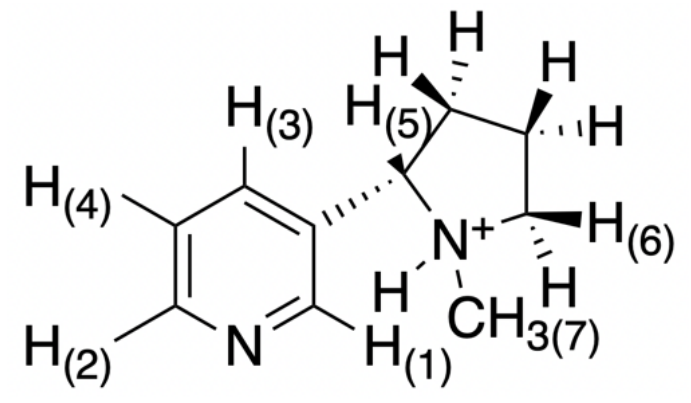

$\delta \Delta \max (p p m)$

\begin{tabular}{lllllllll}
\hline & H1 & H2 & H3 & H4 & H5 & H6 & H7 & $\mathrm{K}_{\mathrm{d}}(\mu \mathrm{M})$ \\
Compound 1 (sCx4) & 0.37 & 0.31 & 0.62 & 0.37 & 0.97 & $\mathrm{n} / \mathrm{a}$ & 0.89 & $96 \pm 6$ \\
Compound 2 (1-formyl) & 0.62 & 0.64 & 1.12 & 0.83 & 1.45 & 1.74 & 1.12 & $404 \pm 17$ \\
Compound 6 (1,2-formyl) & 0.66 & 0.97 & 1.40 & 1.21 & 1.35 & 1.29 & 0.88 & $249 \pm 6$ \\
Compound 4 (1,3-formyl) & 0.55 & 0.81 & 1.25 & 1.06 & 1.22 & 1.35 & 0.98 & $235 \pm 4$ \\
Compound 3 (1-nitro) & 0.68 & 1.19 & 1.60 & 1.55 & 1.28 & 1.37 & 0.92 & $152 \pm 5$ \\
Compound 7 (1,2-nitro) & 0.72 & 1.49 & 1.75 & 1.93 & 1.05 & 0.80 & 0.60 & $245 \pm 3$ \\
Compound 5 (1,3-nitro) & 0.66 & 1.85 & 2.15 & 2.40 & 1.01 & 0.81 & 0.67 & $390 \pm 6$ \\
\hline
\end{tabular}




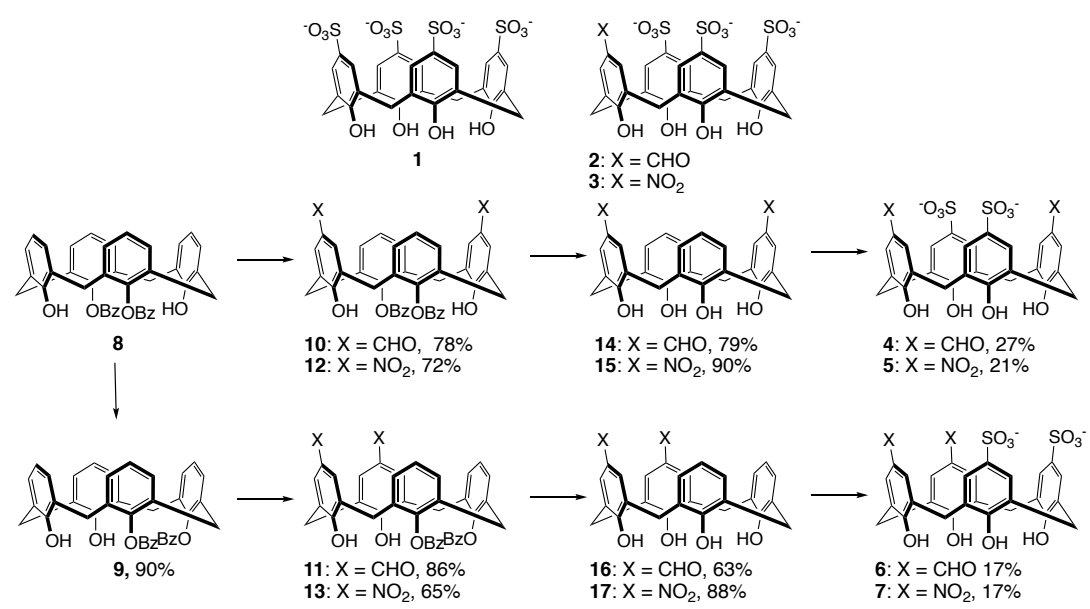

Figure 1: Synthesis scheme 
a.
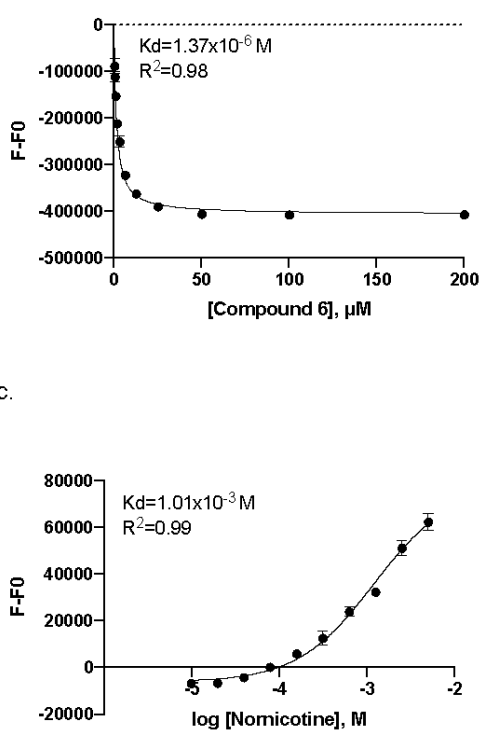

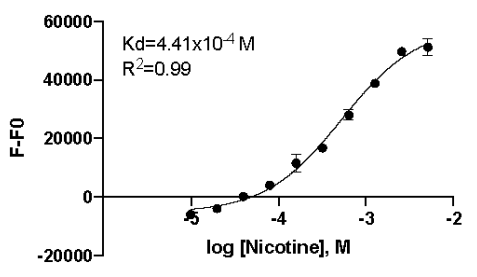

d.

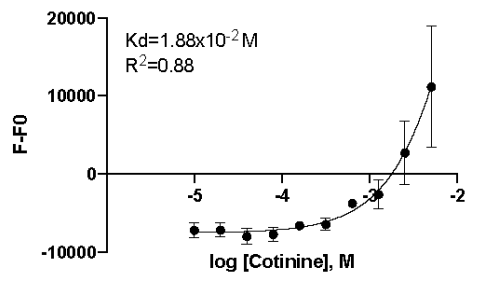

Figure 2: Fluorescence-based indicator displacement assays provide ready access to hostguest binding constants. Exemplary data for fluorescence-based studies of compound $\mathbf{6}$ with nicotine, nornicotine and cotinine. a) Direct titration between LCG $(0.25 \mu \mathrm{M})$ and compound $6(0-200 \mathrm{mM})$ and the competitive titration of b) nicotine $(0-5 \mathrm{mM})$ titrated into the host-LCG complex, c) nornicotine $(0-5 \mathrm{mM})$ titrated into the host-LCG complex for and $\mathrm{d})$ cotinine $(0-5 \mathrm{mM})$ titrated into the host-LCG complex. Buffer $=10 \mathrm{mM}$ phospahe buffer, $\mathrm{pH}$ 7.4. See Supporting Information for data for all host-guest pairs.) 
I.

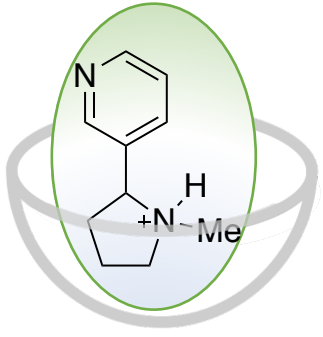

II.

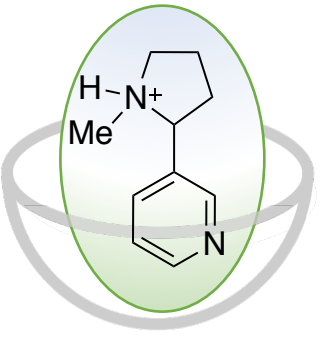

III.

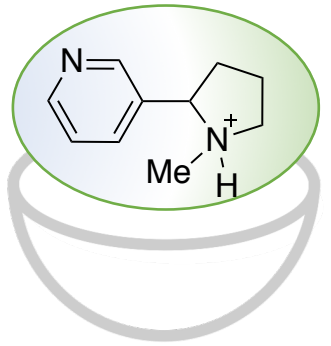

Figure 3: Possible binding motifs of nicotine with the host library 
Supporting information

for

Calix[4]arene sulfonate hosts selectively modified on the upper rim: A study of nicotine binding strength and geometry

Table of Contents

1. General information and materials........................................................... 2

2. ${ }^{1}$ H NMR, ${ }^{13}$ C NMR of novel compounds $(4-7,10-17)$................................. 2

2.1. ${ }^{1} \mathrm{H}$ NMR, ${ }^{13} \mathrm{C}$ NMR compound 4, 1,3-diformyl-2,4-disulfocalix[4]arene......................... 3

2.2. ${ }^{1} \mathrm{H}$ NMR, ${ }^{13} \mathrm{C}$ NMR compound 5, 1,3-dinitro-2,4-disulfocalix[4]arene ............................ 4

2.3. ${ }^{1} \mathrm{H}$ NMR, ${ }^{13} \mathrm{C}$ NMR compound 6, 1,2-diformyl-3,4-disulfocalix[4]arene......................... 5

2.4. ${ }^{1} \mathrm{H}$ NMR, ${ }^{13} \mathrm{C}$ NMR compound 7, 1,2-dinitro-3,4-disulfocalix[4]arene ......................... 6

2.5. ${ }^{1} \mathrm{H}$ NMR, ${ }^{13} \mathrm{C}$ NMR compound 14, 1,3-diformylcalix[4]arene ......................................... 7

2.6. ${ }^{1} \mathrm{H}$ NMR, ${ }^{13} \mathrm{C}$ NMR compound 15, 1,3-dinitrocalix[4]arene .......................................... 8

2.7. ${ }^{1} \mathrm{H}$ NMR, ${ }^{13} \mathrm{C}$ NMR compound 16, 1,2-diformylcalix[4]arene ......................................... 9

3. IDA titrations with nicotine, nornicotine and cotinine....................................... 10

3.1. Fluorescence based studies of compound 1 (sCx4) ................................................ 12

3.2. Fluorescence based studies of compound 2 (1-formyl) ............................................. 13

3.3. Fluorescence based studies of compound 3 (1-nitro).............................................. 14

3.4. Fluorescence based studies of compound 4 (1,3-diformyl) ..................................... 15

3.5. Fluorescence based studies of compound 5 (1,3-dinitro) ....................................... 16

3.6. Fluorescence based studies of compound 6 (1,2-diformyl) .................................... 17

3.7. Fluorescence based studies of compound 7 (1,2-dinitro) .......................................... 18

4. ${ }^{1}$ H NMR titration between compound 1-7 and nicotine .................................... 19

4.1. ${ }^{1}$ H NMR titration between compound 1 (sCx4) and nicotine..................................... 19

4.2. ${ }^{1}$ H NMR titration between compound 2 (1-formyl) and nicotine............................... 20

4.3. ${ }^{1}$ H NMR titration between compound 3 (1-nitro) and nicotine ................................ 21

4.4. 1H NMR titration between compound 4 (1,3-formyl) and nicotine............................. 22 
1. General information and materials

${ }^{1} \mathrm{H}$ and ${ }^{13} \mathrm{C}$ NMR were recorded on a Bruker Avance Neo $500 \mathrm{MHz}$ spectrometer unless otherwise indicated, and processed with MestReNova by Mestrelab Research S.L and TopSpin 3.5. All reported chemical shifts were reported in ppm. Deuterated solvents were purchased from Sigma Aldrich. Sodium phosphate buffer $\left(\mathrm{Na}_{2} \mathrm{HPO}_{4} \cdot 7 \mathrm{H}_{2} \mathrm{O} / \mathrm{NaH}_{2} \mathrm{PO}_{4} \cdot \mathrm{H}_{2} \mathrm{O}, 50 \mathrm{mM}, \mathrm{pH} 7.4\right)$ in $\mathrm{D}_{2} \mathrm{O}$ was prepared. Titrations and dilutions were conducted in a Nunc ${ }^{\mathrm{TM}} 384-$ Well, Non-Treated, FlatBottom, Optical Polymer Base Microplates.

2. ${ }^{1} \mathrm{H}$ NMR, ${ }^{13} \mathrm{C}$ NMR of novel compounds $(4-7,10-17)$ 
2.1. ${ }^{1} \mathrm{H}$ NMR, ${ }^{13} \mathrm{C}$ NMR compound 4, 1,3-diformyl-2,4-disulfocalix[4]arene

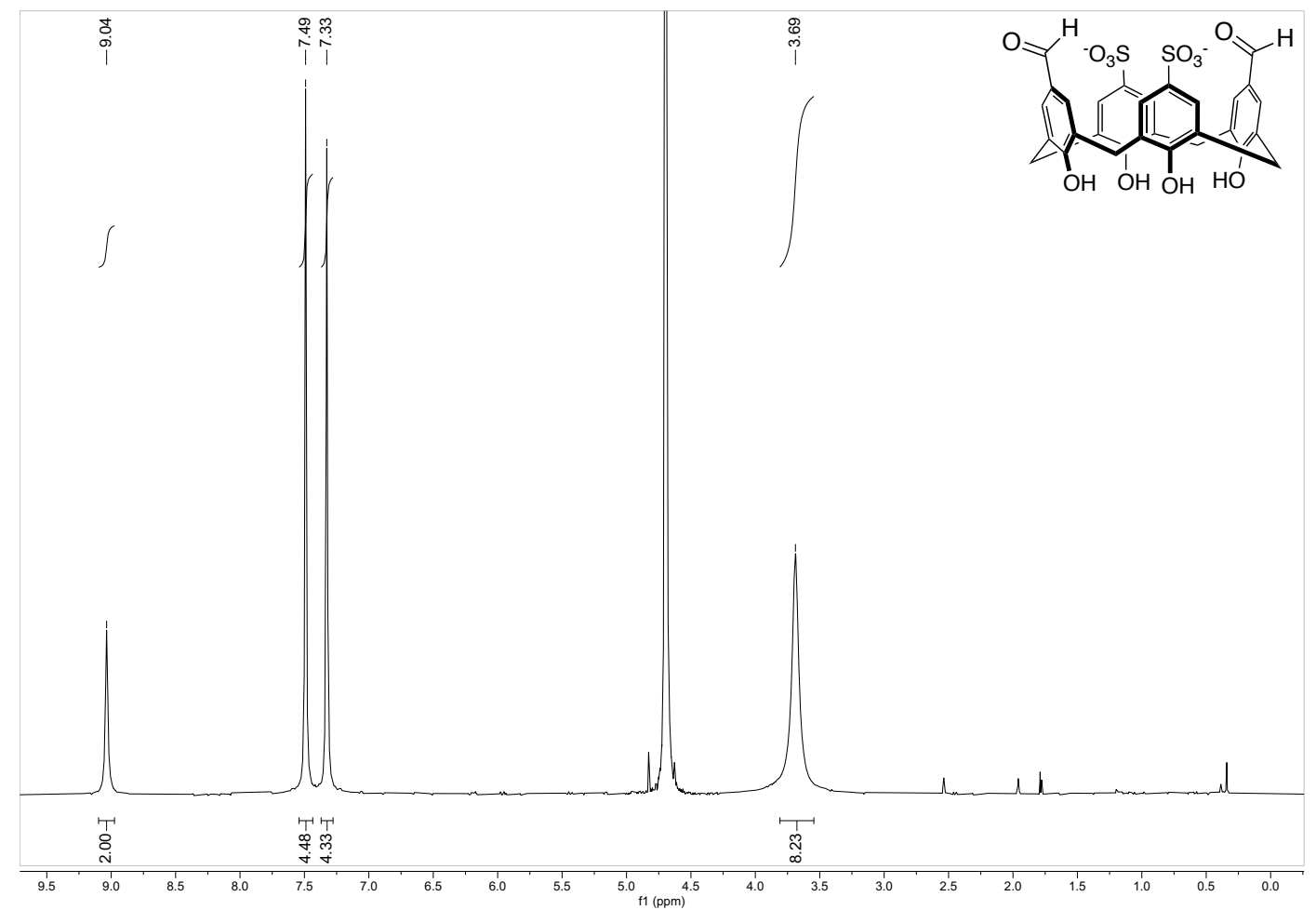

Figure $\mathrm{S} 1:{ }^{1} \mathrm{H}$ NMR spectrum of compound $4(300 \mathrm{MHz})$ in $\mathrm{D}_{2} \mathrm{O}$

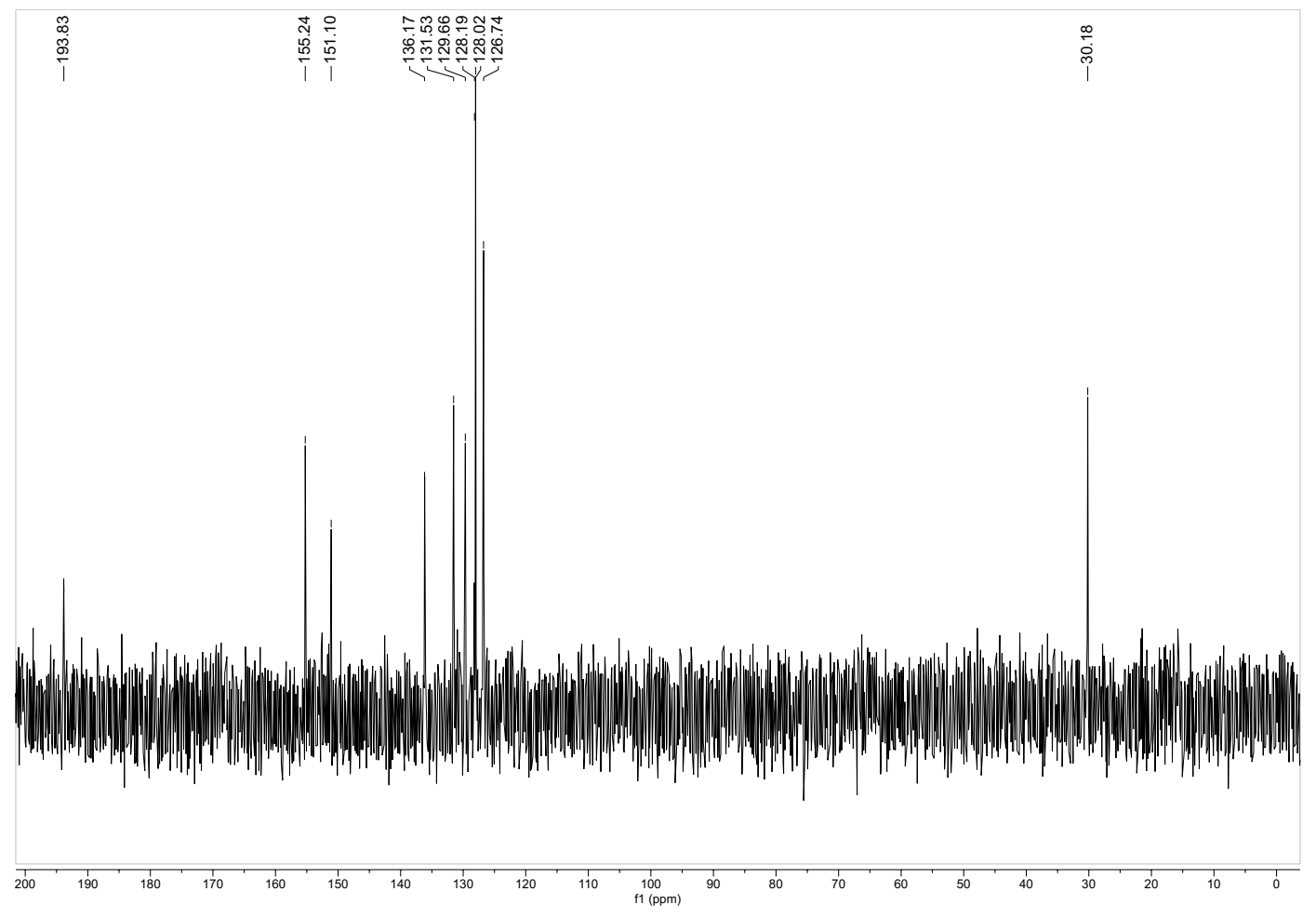

Figure S2: ${ }^{13} \mathrm{C}$ NMR spectrum of compound $4(300 \mathrm{MHz})$ in $\mathrm{D}_{2} \mathrm{O}$ 
2.2. ${ }^{1} \mathrm{H}$ NMR, ${ }^{13} \mathrm{C}$ NMR compound 5, 1,3-dinitro-2,4-disulfocalix[4]arene

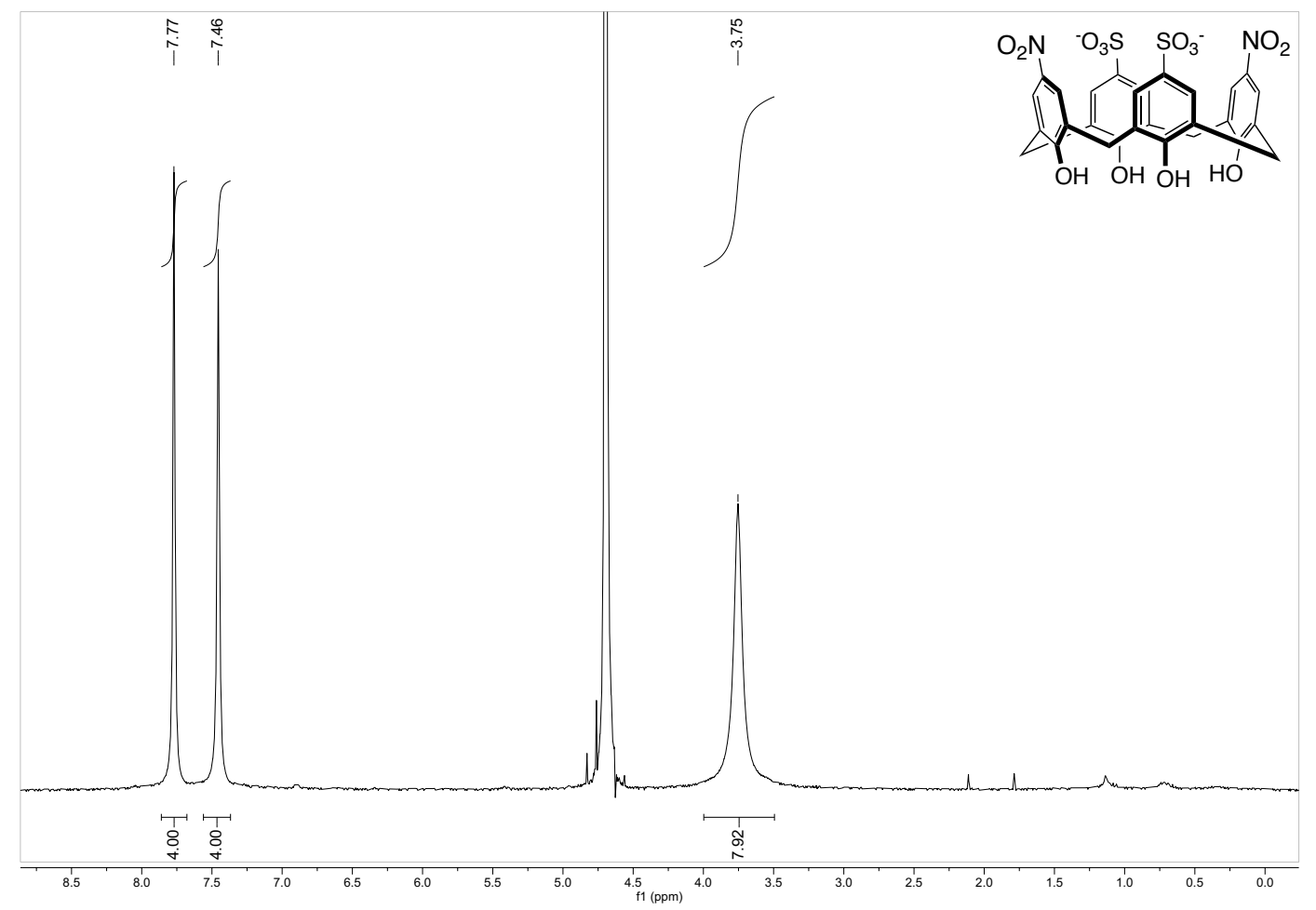

Figure S3: ${ }^{1} \mathrm{H}$ NMR spectrum of compound $5(300 \mathrm{MHz})$ in $\mathrm{D}_{2} \mathrm{O}$
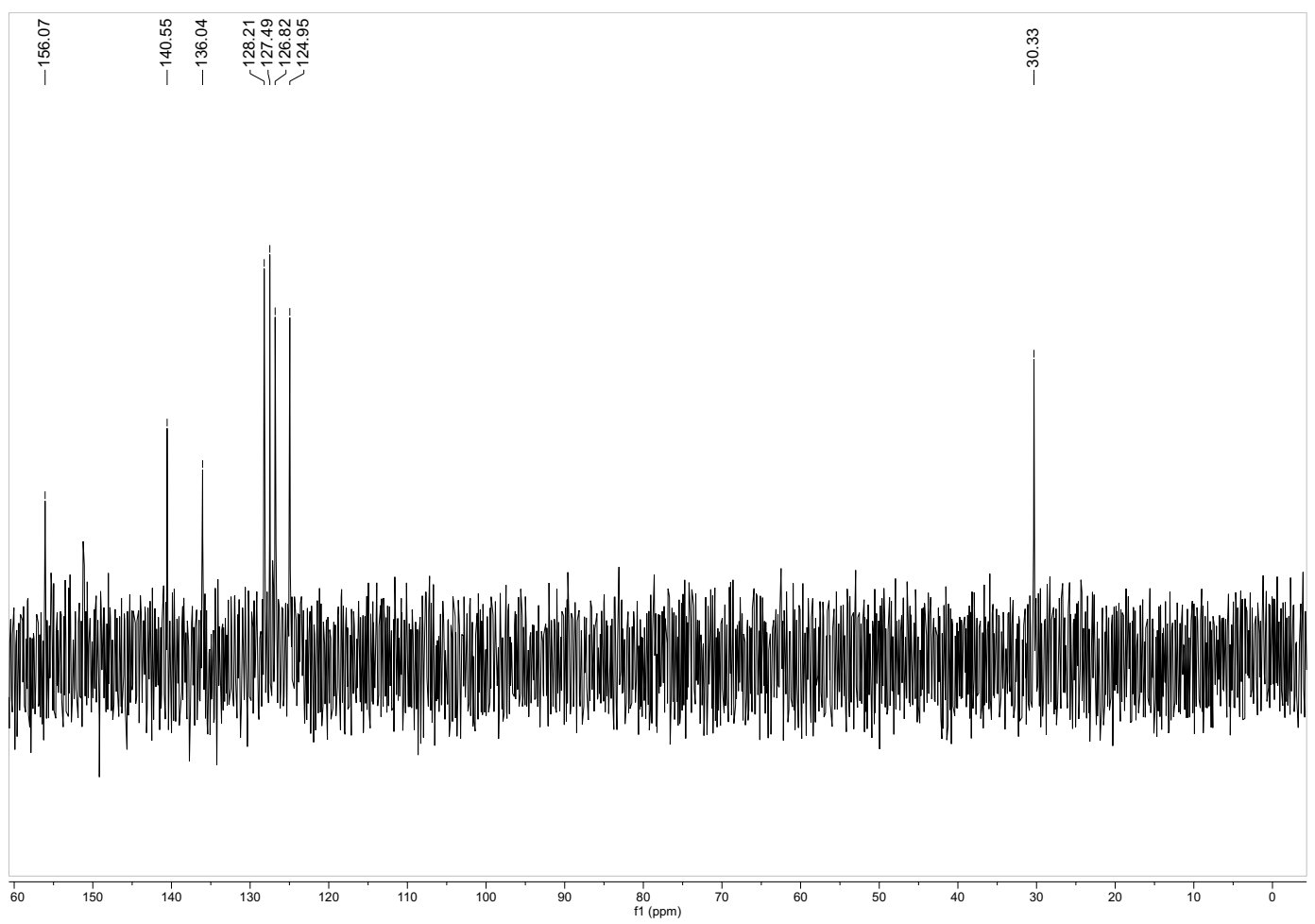

Figure S4: ${ }^{13} \mathrm{C}$ NMR spectrum of compound $5(300 \mathrm{MHz})$ in $\mathrm{D}_{2} \mathrm{O}$ 
2.3. ${ }^{1} \mathrm{H}$ NMR, ${ }^{13} \mathrm{C}$ NMR compound 6, 1,2-diformyl-3,4-disulfocalix[4]arene

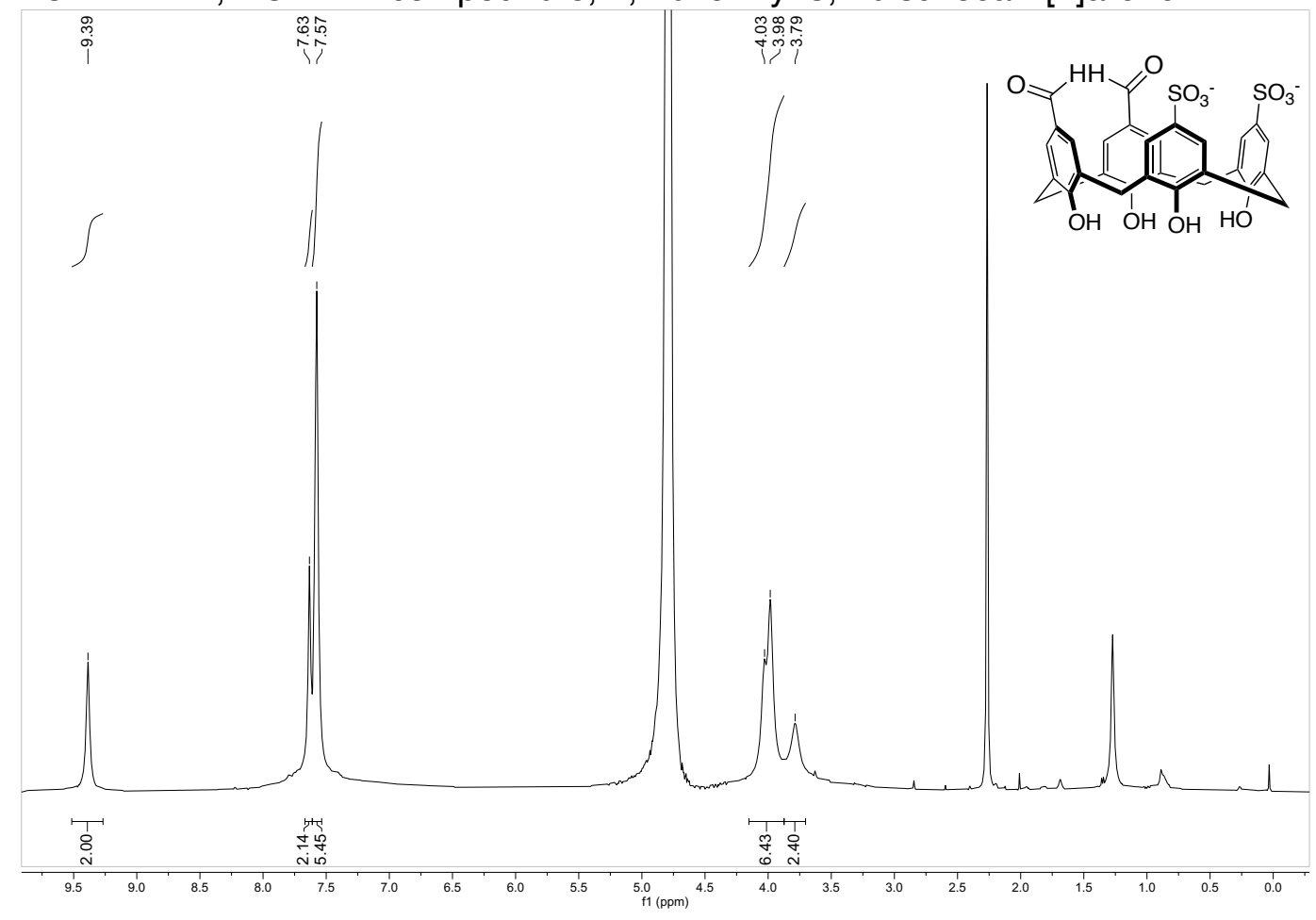

Figure S5: ${ }^{1} \mathrm{H}$ NMR spectrum of compound $6(500 \mathrm{MHz})$ in $\mathrm{D}_{2} \mathrm{O}$
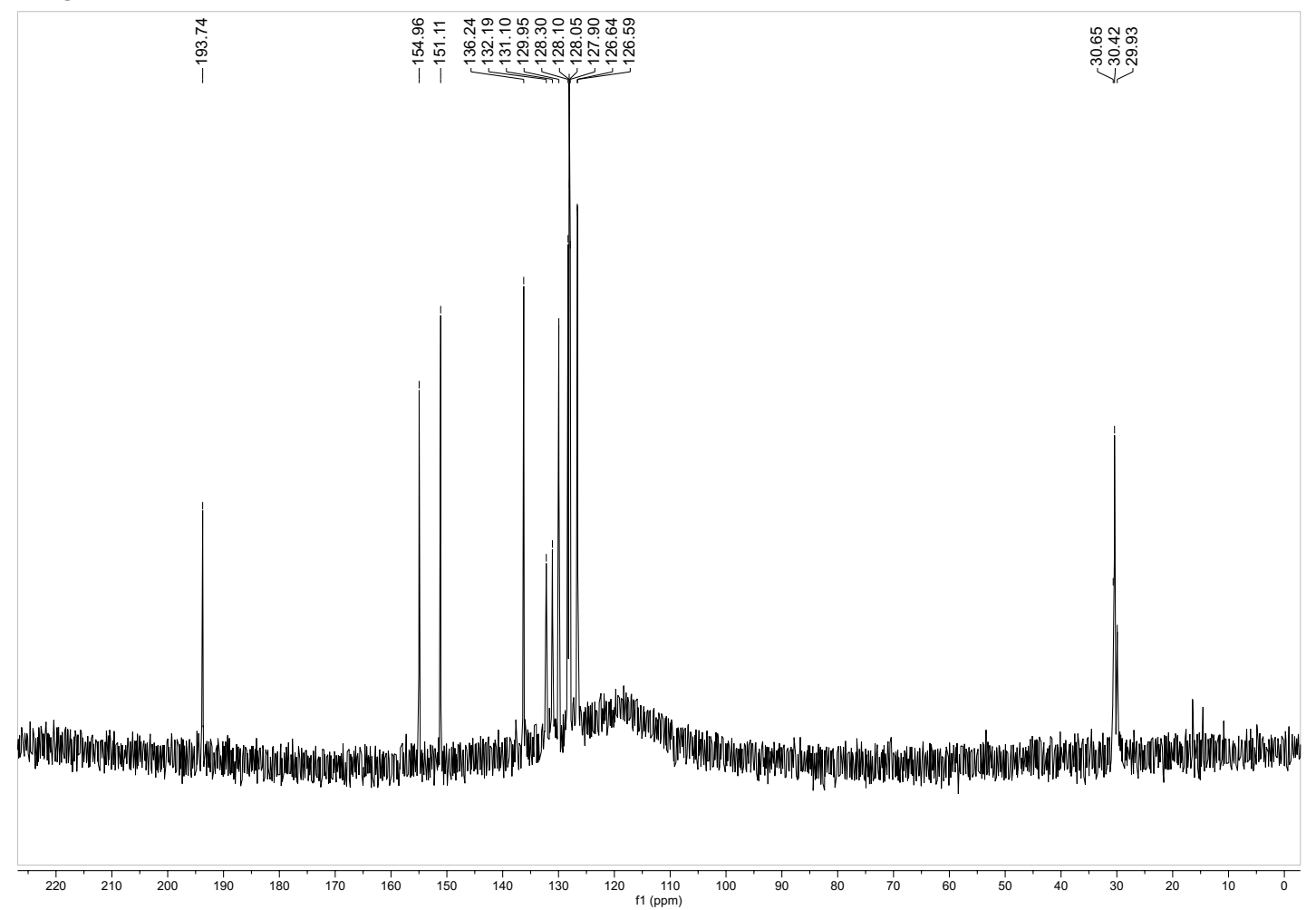

Figure S6: ${ }^{13} \mathrm{C}$ NMR spectrum of compound $6(500 \mathrm{MHz})$ in $\mathrm{D}_{2} \mathrm{O}$ 
2.4. ${ }^{1} \mathrm{H}$ NMR, ${ }^{13} \mathrm{C}$ NMR compound 7, 1,2-dinitro-3,4-disulfocalix[4]arene

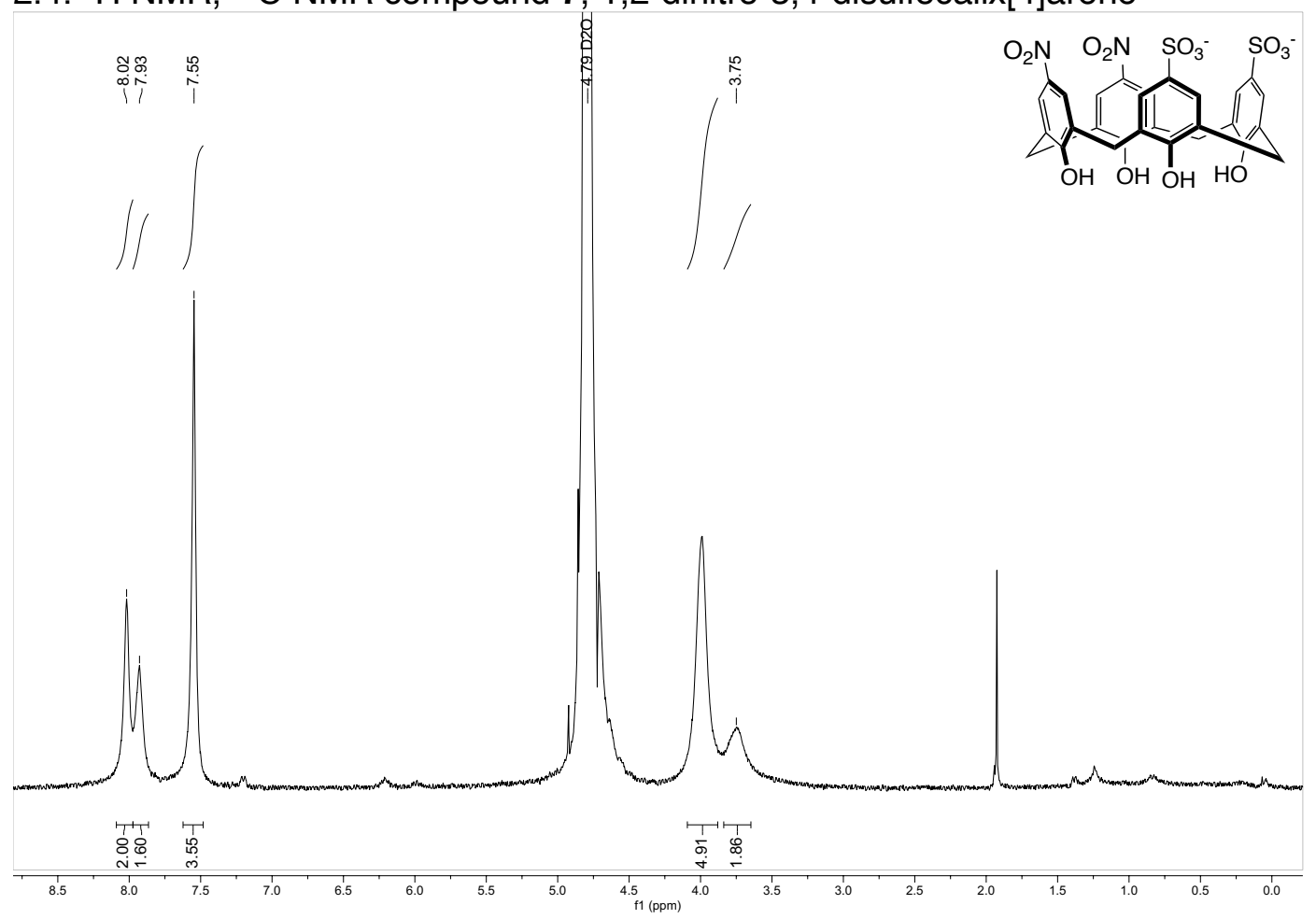

Figure S7: ${ }^{1} \mathrm{H}$ NMR spectrum of compound 7 (300 MHz) in $\mathrm{D}_{2} \mathrm{O}$

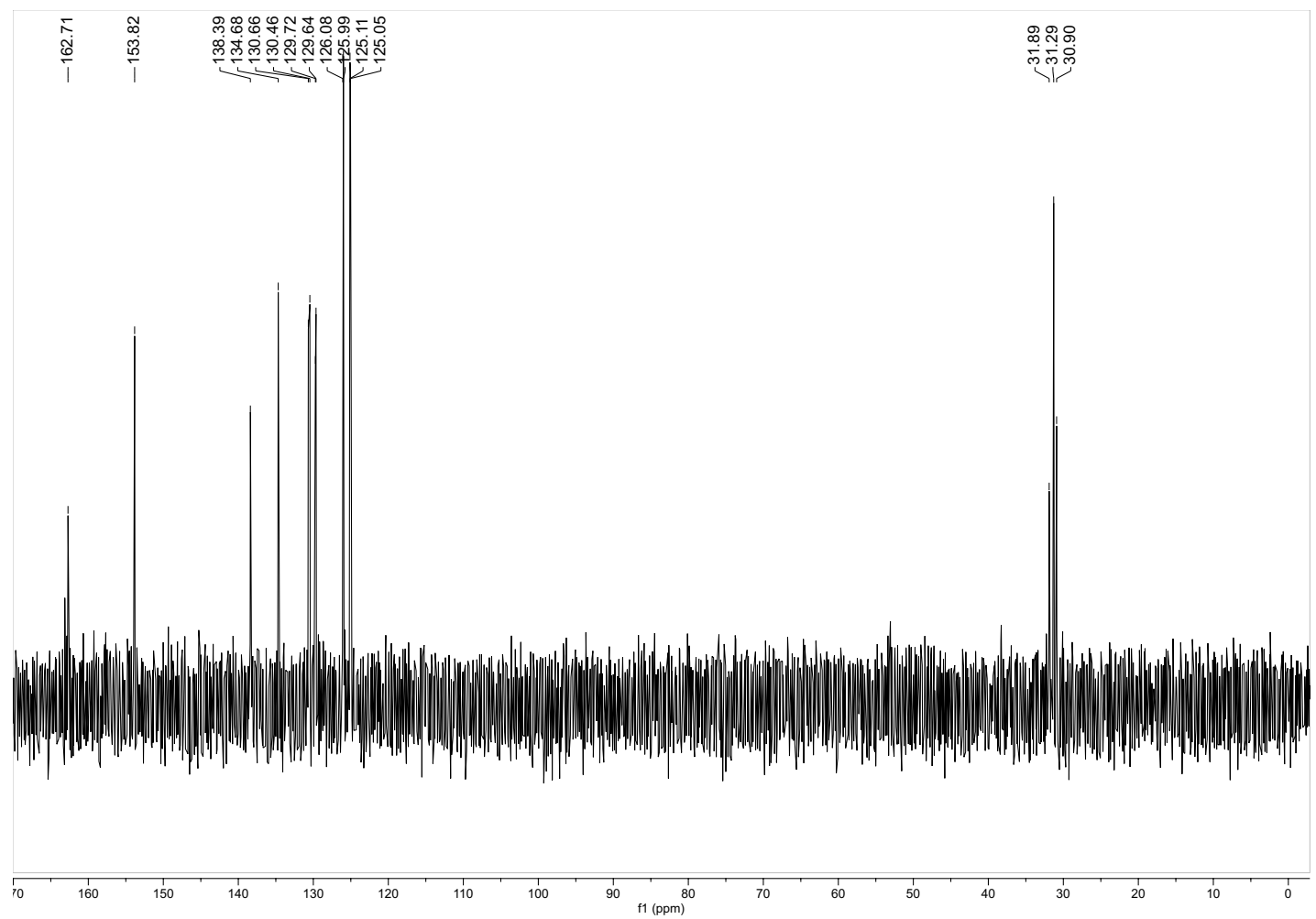

Figure S8: ${ }^{13} \mathrm{C}$ NMR spectrum of compound $7(500 \mathrm{MHz})$ in $\mathrm{D}_{2} \mathrm{O}$ 
2.5. ${ }^{1} \mathrm{H}$ NMR, ${ }^{13} \mathrm{C}$ NMR compound 14, 1,3-diformylcalix[4]arene

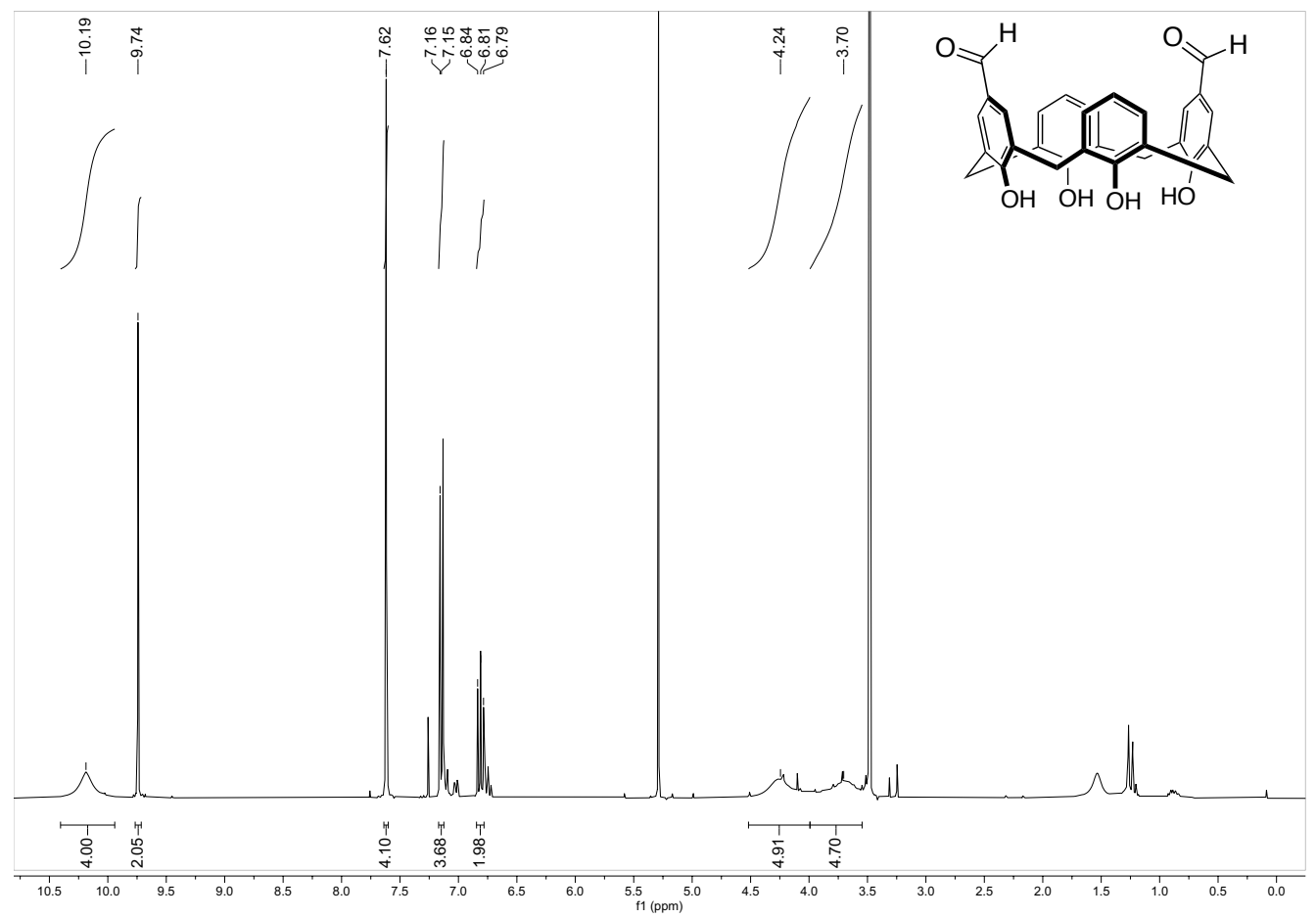

Figure S9: ${ }^{1} \mathrm{H}$ NMR spectrum of compound $14(300 \mathrm{MHz})$ in $\mathrm{D}_{2} \mathrm{O}$

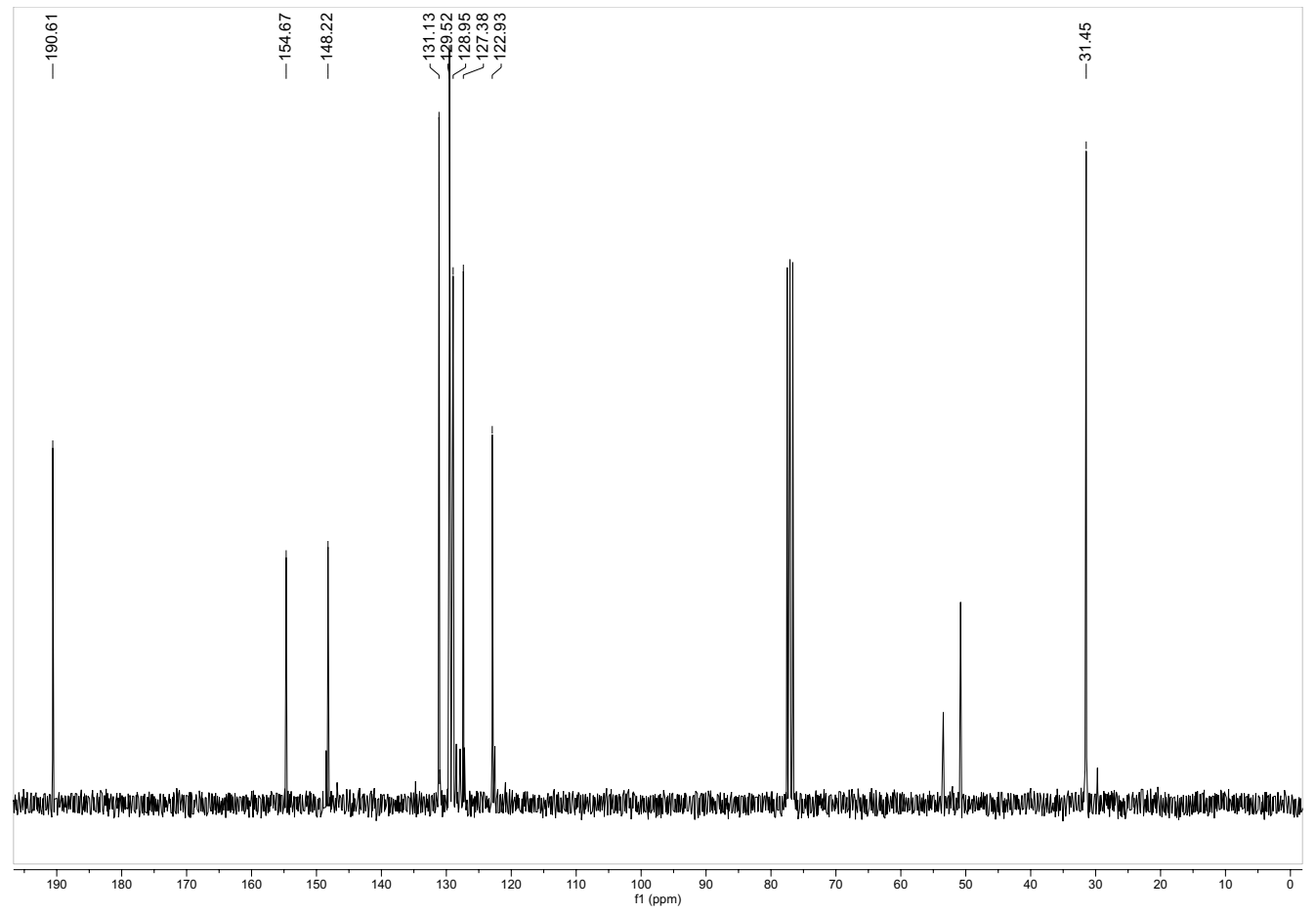

Figure $\mathrm{S} 10:{ }^{13} \mathrm{C}$ NMR spectrum of compound $14(300 \mathrm{MHz})$ in $\mathrm{D}_{2} \mathrm{O}$ 
2.6. ${ }^{1} \mathrm{H}$ NMR, ${ }^{13} \mathrm{C}$ NMR compound 15, 1,3-dinitrocalix[4]arene

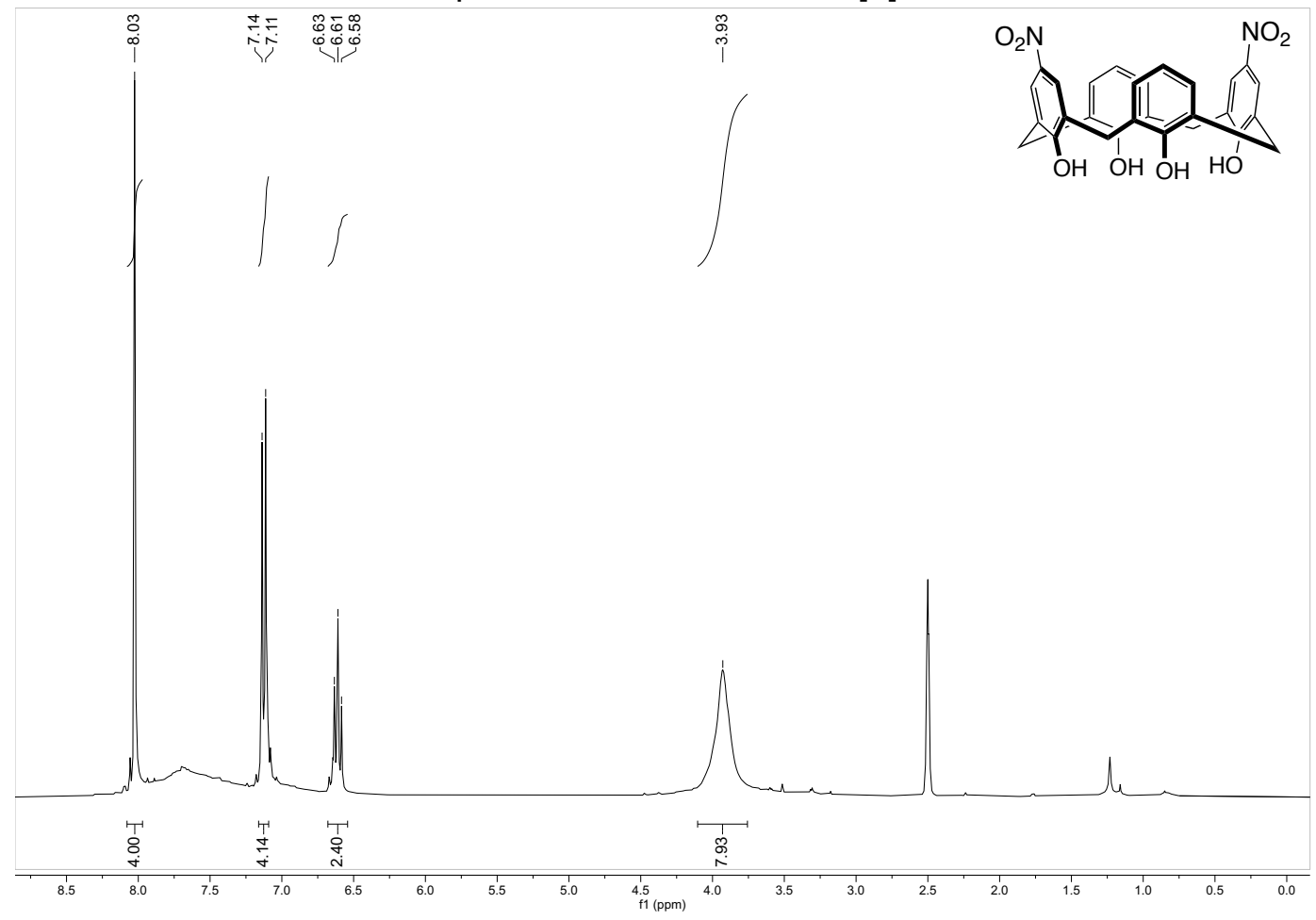

Figure S11: ${ }^{1} \mathrm{H}$ NMR spectrum of compound $15(300 \mathrm{MHz})$ in $\mathrm{D}_{2} \mathrm{O}$

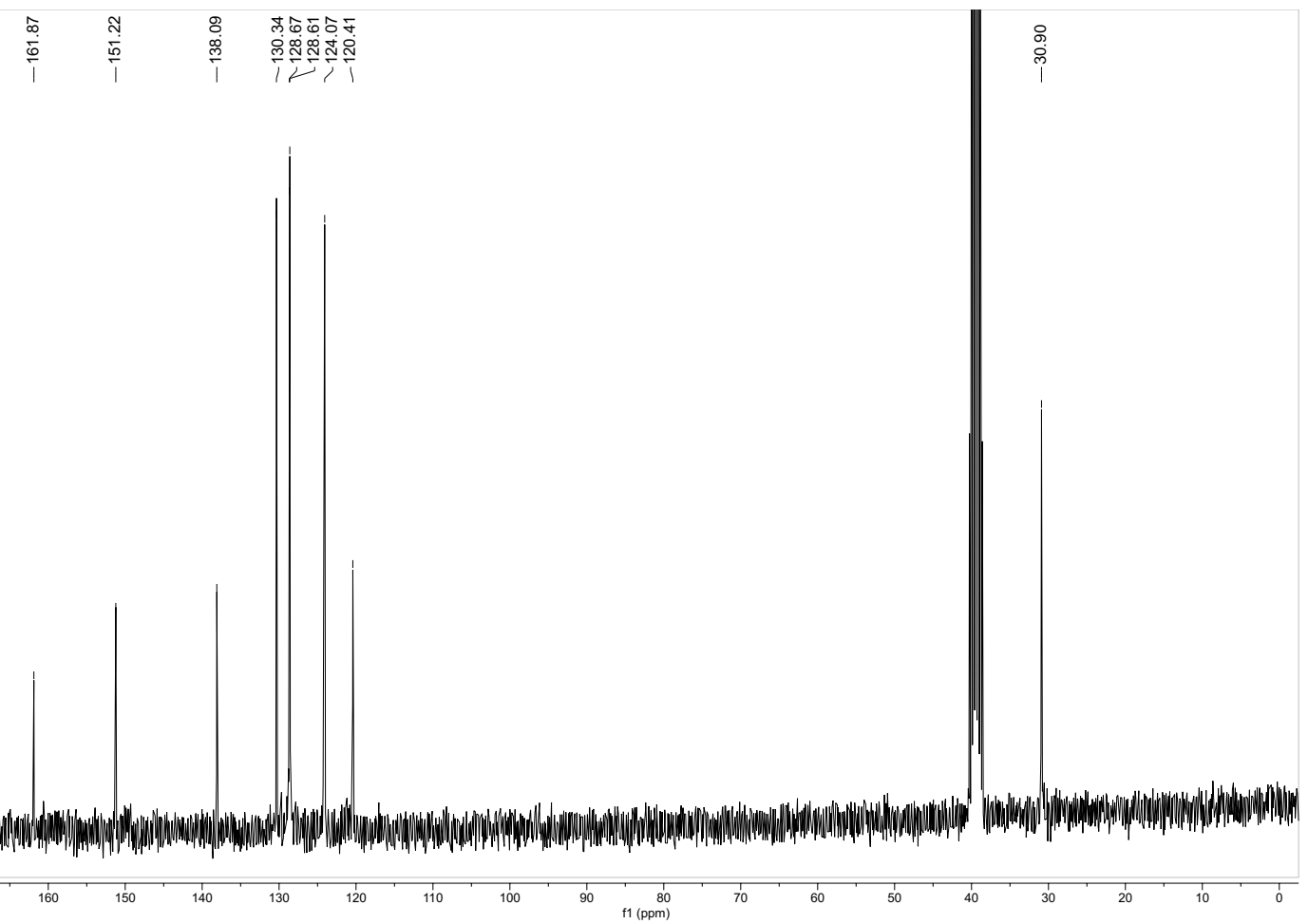

Figure $\mathrm{S} 12:{ }^{13} \mathrm{C}$ NMR spectrum of compound $15(300 \mathrm{MHz})$ in $\mathrm{D}_{2} \mathrm{O}$ 
2.7. ${ }^{1} \mathrm{H}$ NMR, ${ }^{13} \mathrm{C}$ NMR compound 16, 1,2-diformylcalix[4]arene

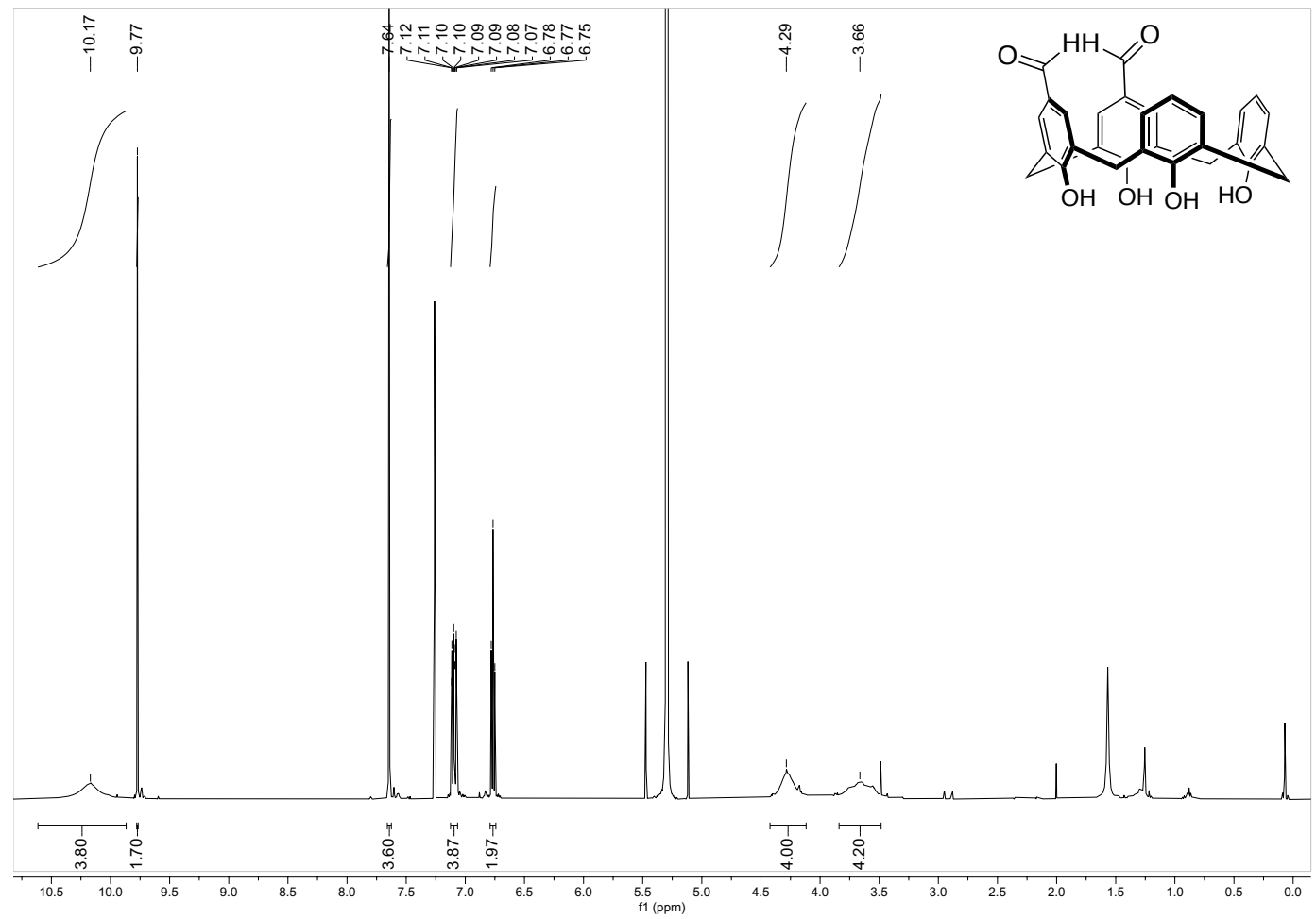

Figure S13: ${ }^{1} \mathrm{H}$ NMR spectrum of compound $16(500 \mathrm{MHz})$ in $\mathrm{D}_{2} \mathrm{O}$

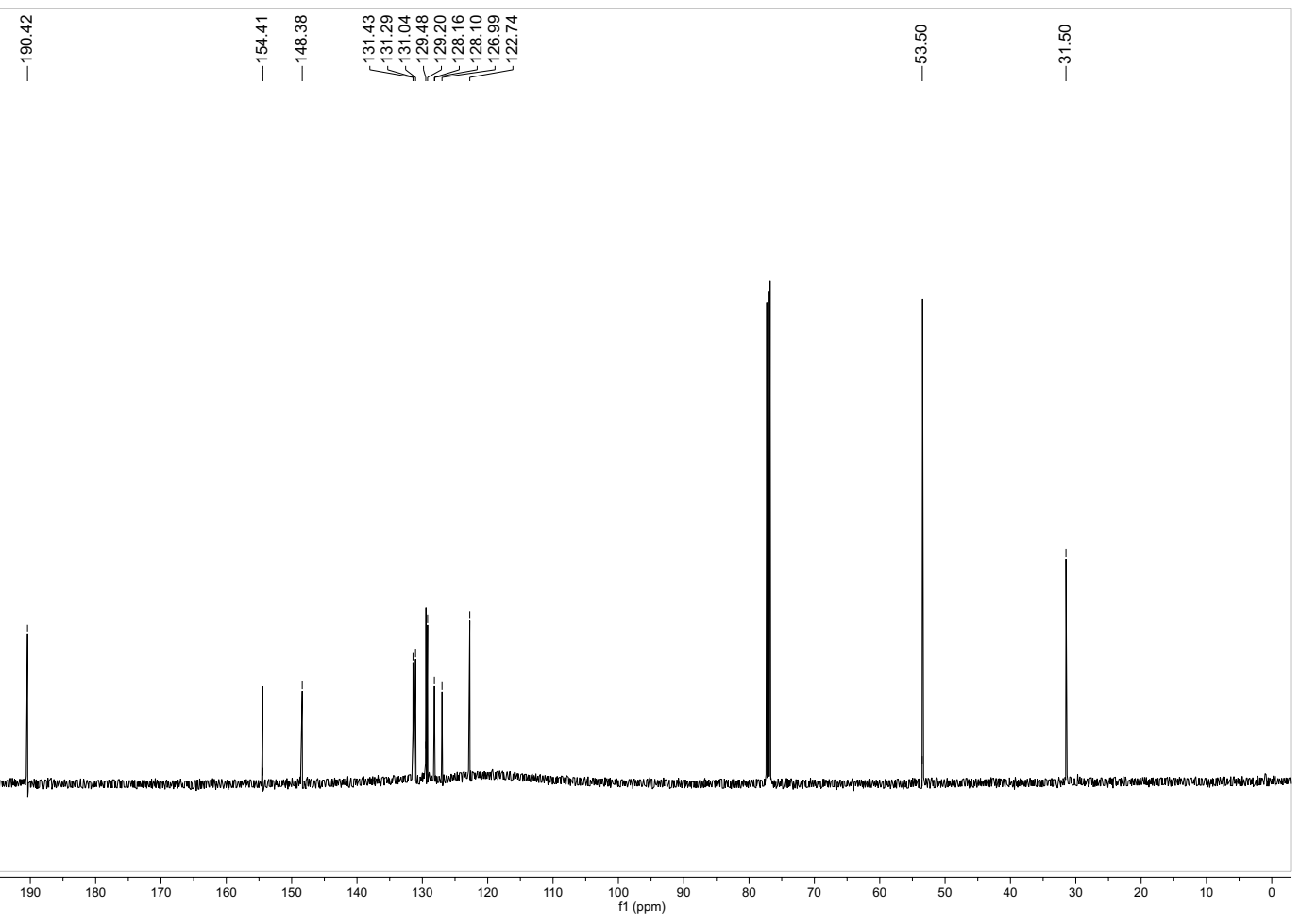

Figure $\mathrm{S} 14:{ }^{13} \mathrm{C}$ NMR spectrum of compound $16(500 \mathrm{MHz})$ in $\mathrm{D}_{2} \mathrm{O}$ 
3. IDA titrations with nicotine, nornicotine and cotinine

The IDAs were conducted in 384 well plates (NUNC, optical black bottom). The fluorescent signal was read on the citation 5 (Software Version 3.05.11) as a fluorescent endpoint measurement. The settings were as followed: Excitation: 369/20, Emission: 475/20. Optics: Top, Gain: extended. Light Source: Xenon Flash, Lamp Energy: High, Extended Dynamic Range. Read Speed: Normal, Delay: $100 \mathrm{msec}$, Measurements/Data Point: 10. Read Height: $10.5 \mathrm{~mm}$. All wells has to final total volume of $50 \mu \mathrm{L}$. To measure the dye control, three wells were titrated to a concentration of $0.25 \mu \mathrm{M}$ LCG in $10 \mathrm{mM}$ phospahe buffer, $\mathrm{pH}$ 7.4. To measure the host control, three wells were titrated to a concentration of $5 \mu \mathrm{M}$ host in $10 \mathrm{mM}$ buffer. For the direct titration, a serial dilution was done from $200 \mu \mathrm{M}$ to $0.01 \mu \mathrm{M}$ host into $0.25 \mu \mathrm{M}$ LCG in $10 \mathrm{mM}$ buffer. For the competitive titrations, a serial dilution was done from $5 \mathrm{mM}$ to $0.01 \mathrm{mM}$ guest into $5 \mu \mathrm{M}$ host, $0.25 \mu \mathrm{M}$ LCG in $10 \mathrm{mM}$ buffer. All the IDA data is analysed in GraphPad Prism Version 8.3.0 (328). One exemplary replicate is shown for each host, the experiments for nicotine and nornicotine are done in duplicates of triplicates and the experiments for cotinine are done in duplicates of duplicates.

\section{Calculations}

Outliers

Outliers are determined by the Dixon's Q-test, Equation 1, where the gap is the absolute difference between the outlier in question and the closest number to it. With three observations and at $90 \%$ confidence, $Q>0.941=Q_{90 \%, n=3}$, we conclude the data point is an outlier.

Equation 1. Dixon's Q-test

$$
Q=\frac{g a p}{\text { range }}
$$

The standard error

The standard error is calculated to each triplicate, Equation 2.

\section{Equation 2. Standard error}

$$
S D_{K_{i}}=\left(\ln (10) * 10^{\log K_{i}}\right) * S D_{\log K_{i}}
$$

$\mathrm{SD}_{\mathrm{Ki}}=$ Standard error of $\mathrm{K}_{\mathrm{i}}$

$\log \mathrm{Ki}=$ Value of the log

$\mathrm{SD}_{\text {logki }}=$ Standard error of the $\log \mathrm{Ki}$ 
The total standard error

The total standard error between two the triplicates is calculated by Equation 3.

Equation 3. Total standard error

$$
S D_{\text {total }}=\sqrt{\frac{\left(S D_{1}^{2}+S D_{2}^{2}\right)}{n}}
$$

$\mathrm{SD}_{\text {total }}=$ Standard derivation of both experiments

$\mathrm{SD}_{1} \quad=$ Standard derivation of the first triplicate

$\mathrm{SD}_{2}=$ Standard derivation of the second triplicate

$\mathrm{n} \quad=$ Number of experiments

Curve fit for the direct titration

To curve fit for the direct titration Error! Reference source not found., Equation 4 are used.

Equation 4. Curve fit for the direct titration for a turn off signal

$$
F=F_{\text {max }}-\frac{\left(F_{\max }-F_{\min }\right) *\left([D]+[H]+K_{d}\right)-\sqrt{\left([D]+[H]+K_{d}\right)^{2}-4 *[H] *[D]}}{2 *[D]}
$$

$\mathrm{F} \quad=$ Fitted data point

$\mathrm{F}_{\max } \quad=$ Maximum signal

$\mathrm{F}_{\min }=$ Minimum signal

[D] = Molar concentration of dye in $\mu \mathrm{M}$

$[\mathrm{H}] \quad=$ Molar concentration of host (titrant)

$\mathrm{K}_{\mathrm{d}} \quad=$ Dissociation constant

Curve fit for the competitive titration

$$
\begin{gathered}
\log _{E C 50}=\log \left(10^{\log _{K i}} *\left(1+\frac{[D]}{K_{d}}\right)\right) \\
F=F_{\text {min }}+\left(F_{\text {max }}-F_{\text {min }}\right) /\left(1+10^{\left(X-\log _{E C 50)}\right)}\right.
\end{gathered}
$$

$\log _{E C 50}=\log$ of the concentration of the competitor binding half-way between $F_{\min }$ and $F_{\max }$

$\mathrm{K}_{\mathrm{i}} \quad=$ Equilibrium dissociation constant in Molar

[D] = Concentration of dye in $\mathrm{nM}$

$\mathrm{K}_{\mathrm{d}} \quad=$ Equilibrium dissociation constant of the direct titration

$\mathrm{F} \quad=$ Fitted data point

$F_{\max }=$ Maximum signal

$\mathrm{F}_{\text {min }}=$ Minimum signal 
3.1. Fluorescence based studies of compound 1 (sCx4)

a.

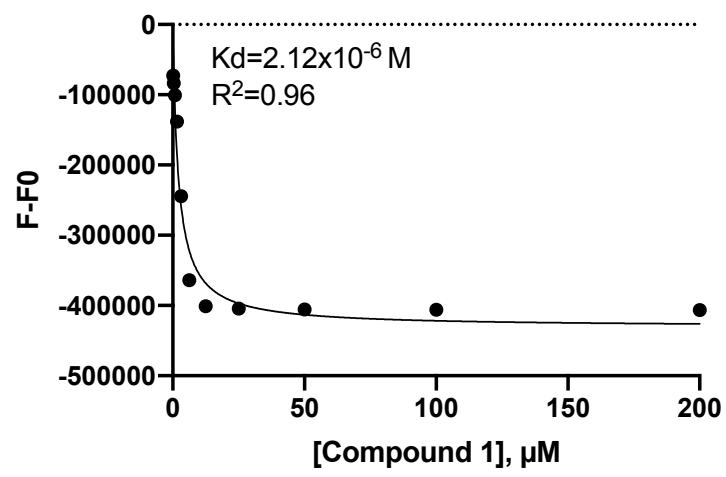

c.

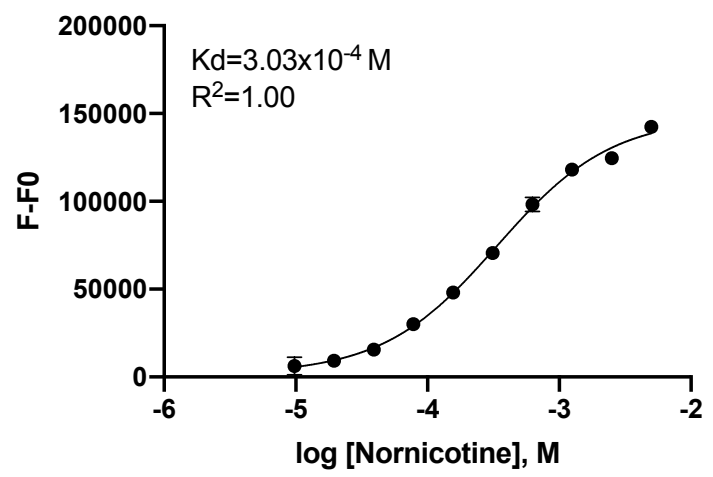

b.

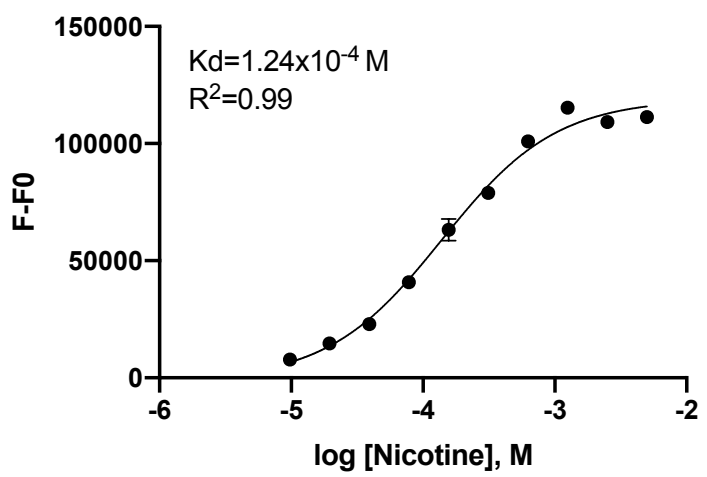

d.

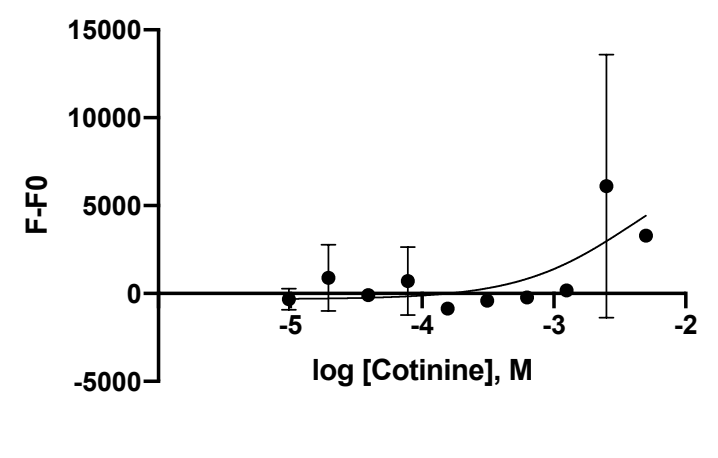

Figure S15: Fluorescence based studies of compound 1 with nicotine, nornicotine and cotinine. a) The direct titration of LCG $(0.25 \mu \mathrm{M})$ with compound $1(0-200 \mathrm{mM})$, and the competitive titrations of b) nicotine $(0-5 \mathrm{mM}), \mathrm{c})$ nornicotine $(0-5 \mathrm{mM})$, and d) cotinine $(0-5 \mathrm{mM})$ titrated into the host-LCG complex (5 $\mu \mathrm{M}$ host, $0.25 \mu \mathrm{M}$ LCG). 
3.2. Fluorescence based studies of compound 2 (1-formyl)

a.

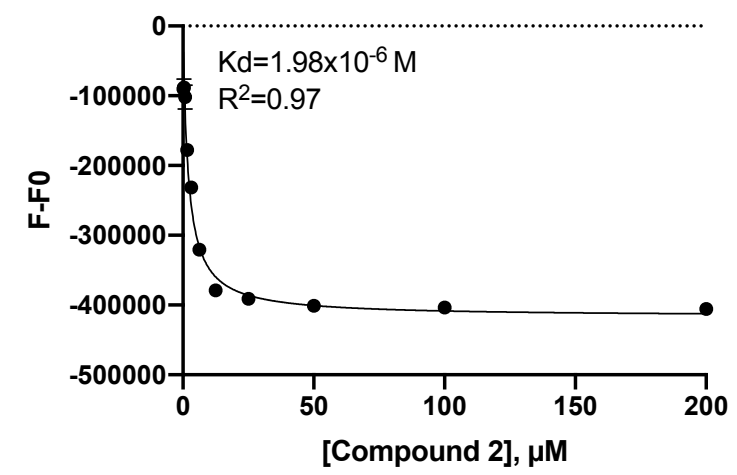

C.

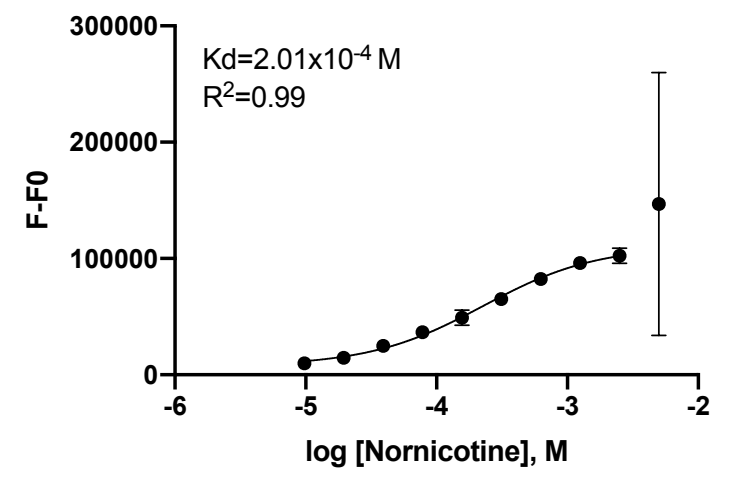

b.

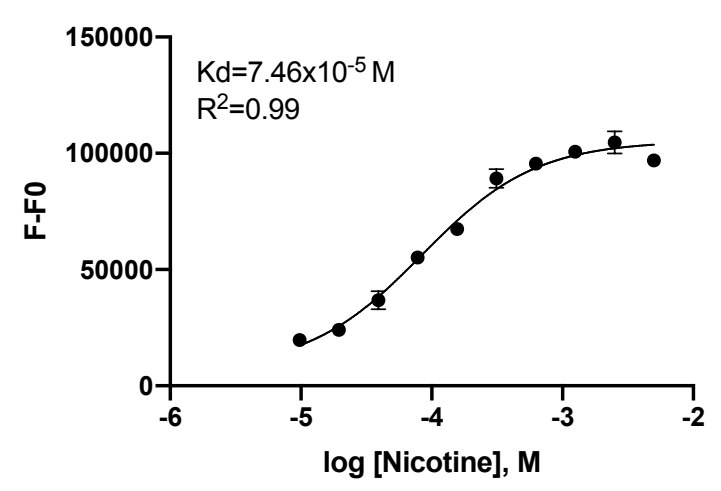

d.

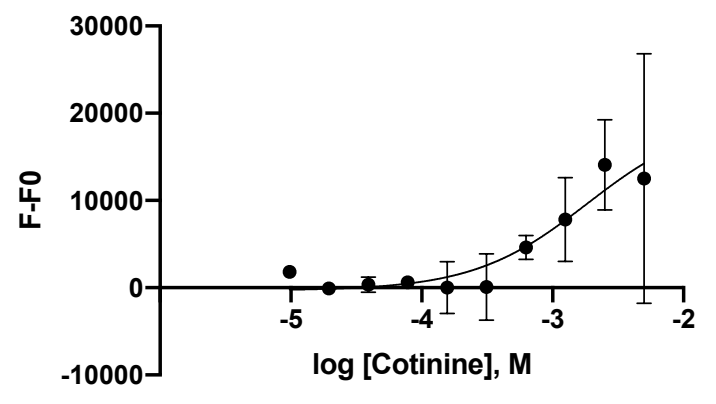

Figure S16: Fluorescence based studies of compound 2 with nicotine, nornicotine and cotinine. a) The direct titration of LCG $(0.25 \mu \mathrm{M})$ with compound $2(0-200 \mathrm{mM})$, and the competitive titrations of b) nicotine $(0-5 \mathrm{mM}), \mathrm{c})$ nornicotine $(0-2.5 \mathrm{mM})$ (The $5 \mathrm{mM}$ concentration was omitted from the fit due to strong deviations of this guest on this concentration), and d) cotinine $(0-5 \mathrm{mM})$ titrated into the host-LCG complex (5 $\mu \mathrm{M}$ host, $0.25 \mu \mathrm{M} \mathrm{LCG})$. 
3.3. Fluorescence based studies of compound 3 (1-nitro)

a.

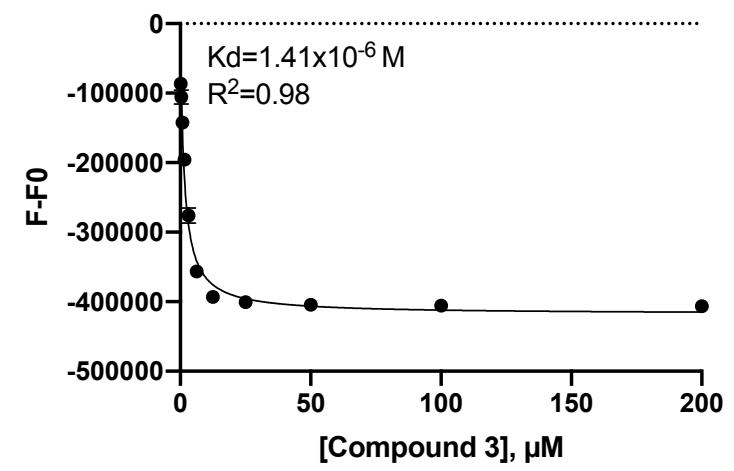

C.

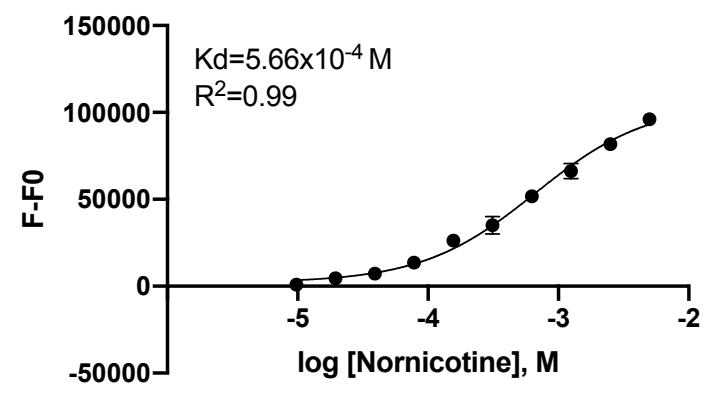

b.

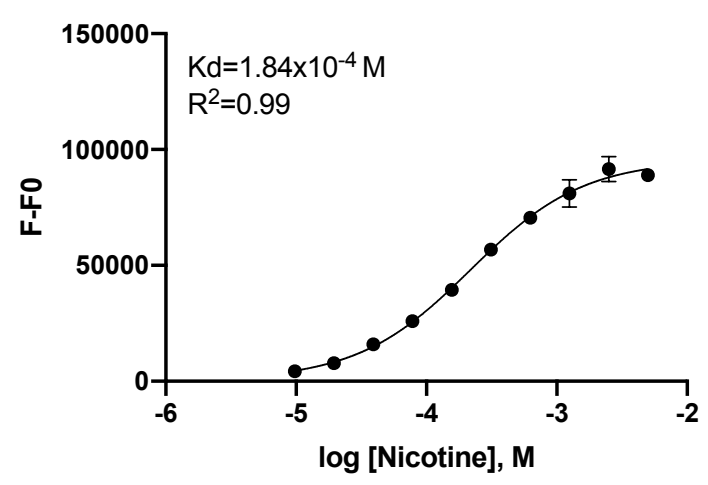

d.

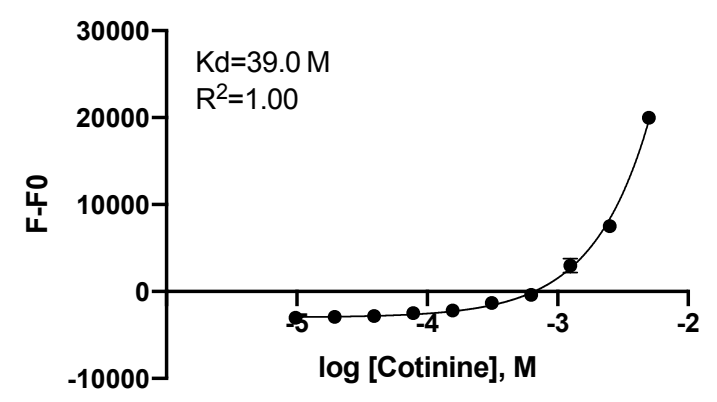

Figure S17: Fluorescence based studies of compound 3 with nicotine, nornicotine and cotinine. a) The direct titration of LCG $(0.25 \mu \mathrm{M})$ with compound $3(0-200 \mathrm{mM})$, and the competitive titrations of b) nicotine $(0-5 \mathrm{mM})$, c) nornicotine $(0-5 \mathrm{mM})$, and d) cotinine $(0-5 \mathrm{mM})$ titrated into the host-LCG complex ( $5 \mu \mathrm{M}$ host, $0.25 \mu \mathrm{M}$ LCG). 
3.4. Fluorescence based studies of compound 4 (1,3-diformyl)

a.

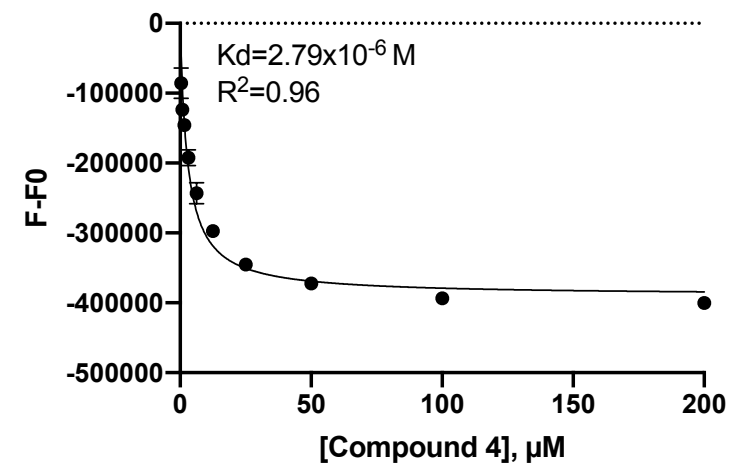

C.

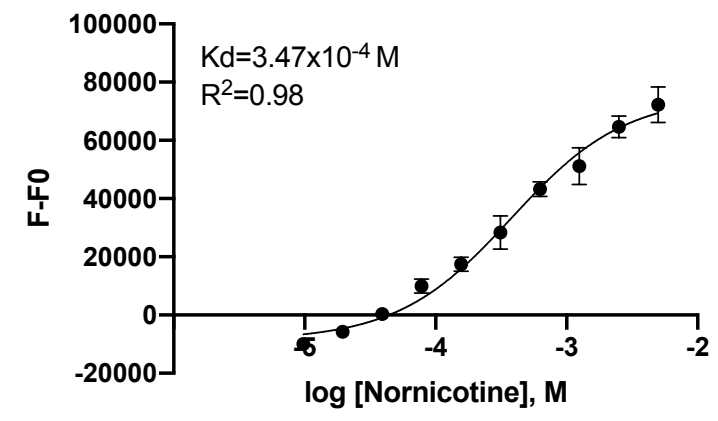

b.

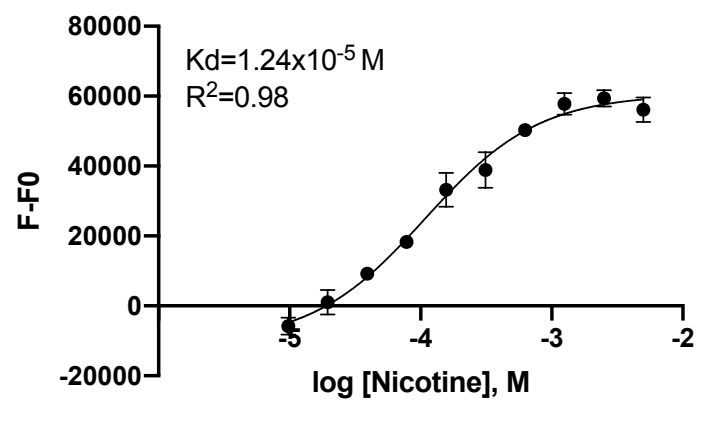

d.

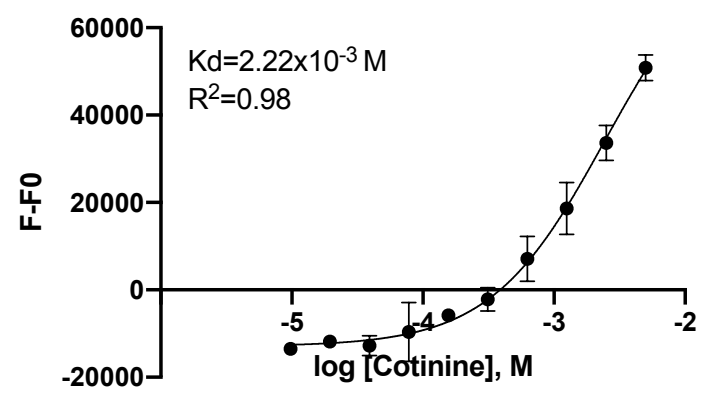

Figure S18: Fluorescence based studies of compound 4 with nicotine, nornicotine and cotinine. a) The direct titration of LCG $(0.25 \mu \mathrm{M})$ with compound $4(0-200 \mathrm{mM})$, and the competitive titrations of b) nicotine $(0-5 \mathrm{mM})$, c) nornicotine $(0-5 \mathrm{mM})$, and d) cotinine $(0-5 \mathrm{mM})$ titrated into the host-LCG complex ( $5 \mu \mathrm{M}$ host, $0.25 \mu \mathrm{M}$ LCG). 
3.5. Fluorescence based studies of compound 5 (1,3-dinitro)

a.

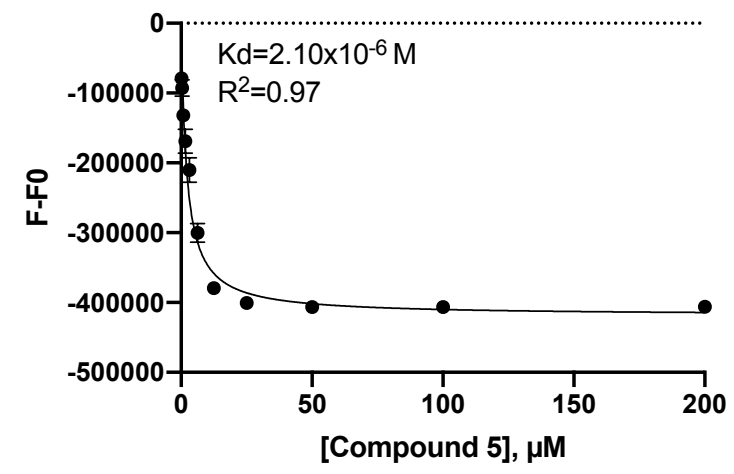

c.

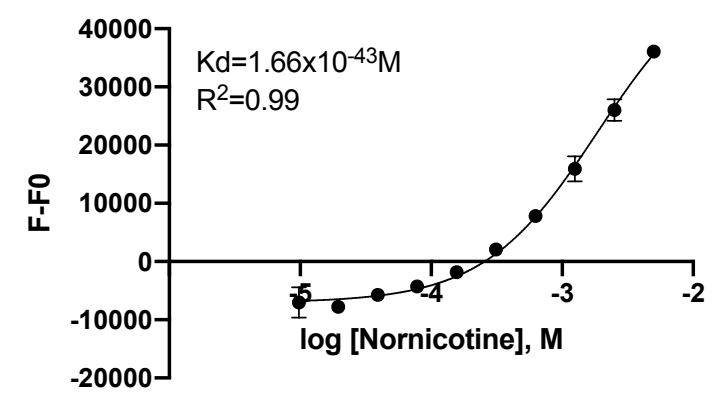

b.

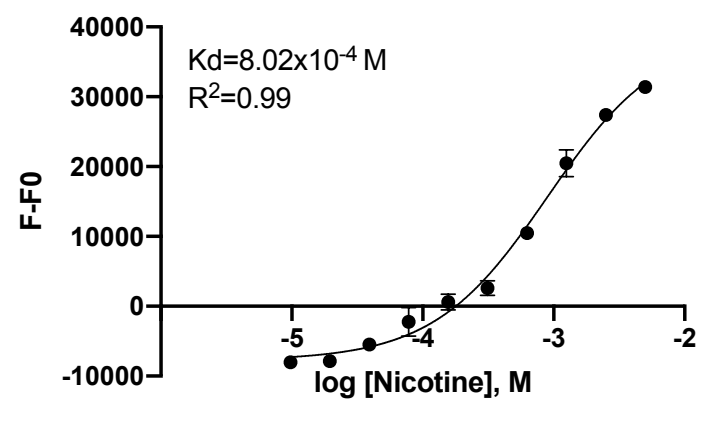

d.

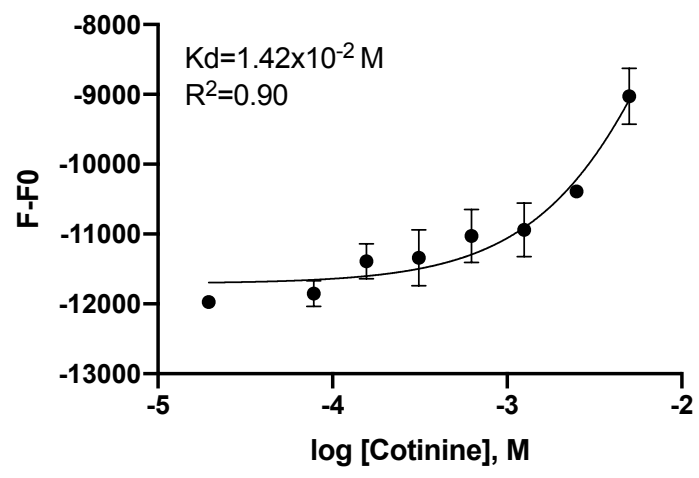

Figure S19: Fluorescence based studies of compound 5 with nicotine, nornicotine and cotinine. a) The direct titration of LCG $(0.25 \mu \mathrm{M})$ with compound $5(0-200 \mathrm{mM})$, and the competitive titrations of b) nicotine $(0-5 \mathrm{mM}), \mathrm{c})$ nornicotine $(0-5 \mathrm{mM})$, and d) cotinine $(0-5 \mathrm{mM})$ titrated into the host-LCG complex (5 $\mu \mathrm{M}$ host, $0.25 \mu \mathrm{M}$ LCG). 
3.6. Fluorescence based studies of compound 6 (1,2-diformyl)

a.

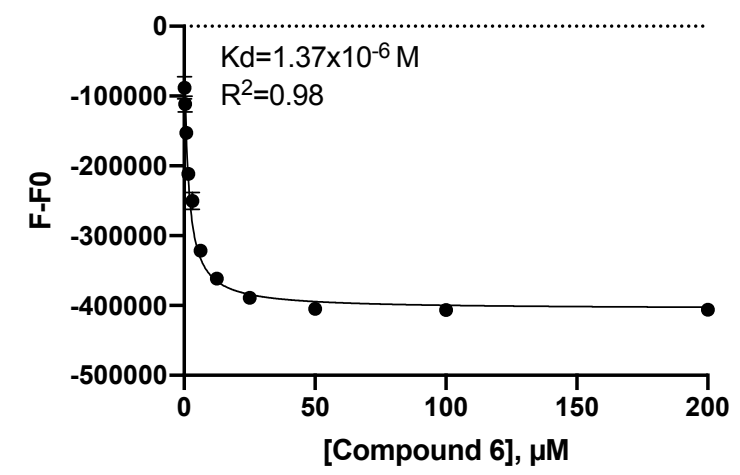

c.

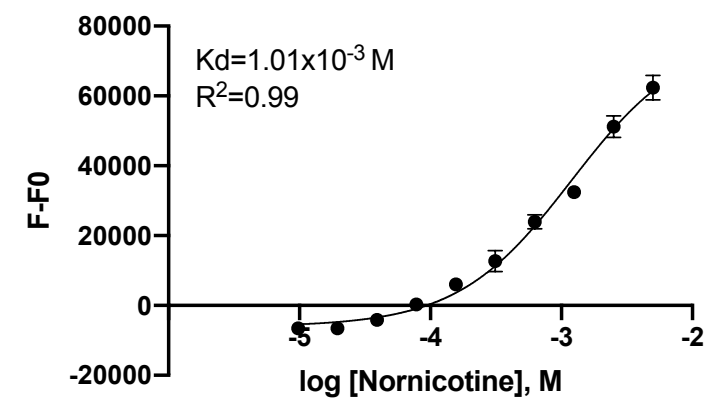

b.

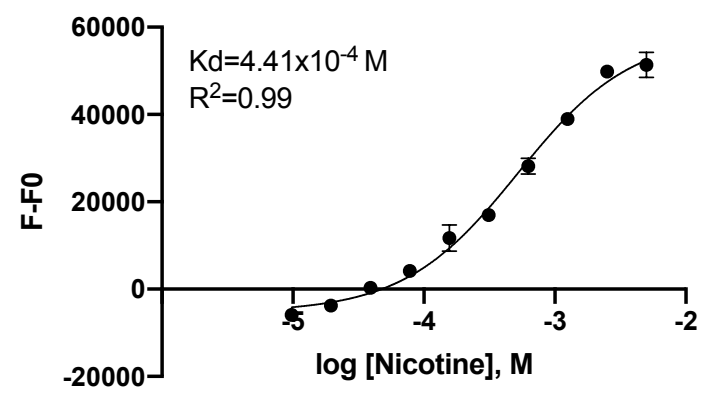

d.

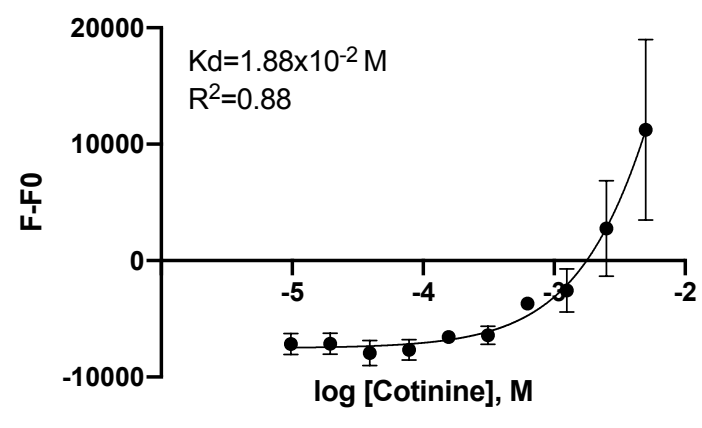

Figure S20: Fluorescence based studies of compound 6 with nicotine, nornicotine and cotinine. a) The direct titration of LCG $(0.25 \mu \mathrm{M})$ with compound $6(0-200 \mathrm{mM})$, and the competitive titrations of b) nicotine $(0-5 \mathrm{mM}), \mathrm{c})$ nornicotine $(0-5 \mathrm{mM})$, and d) cotinine $(0-5 \mathrm{mM})$ titrated into the host-LCG complex ( $5 \mu \mathrm{M}$ host, $0.25 \mu \mathrm{M}$ LCG). 
3.7. Fluorescence based studies of compound 7 (1,2-dinitro)

a.

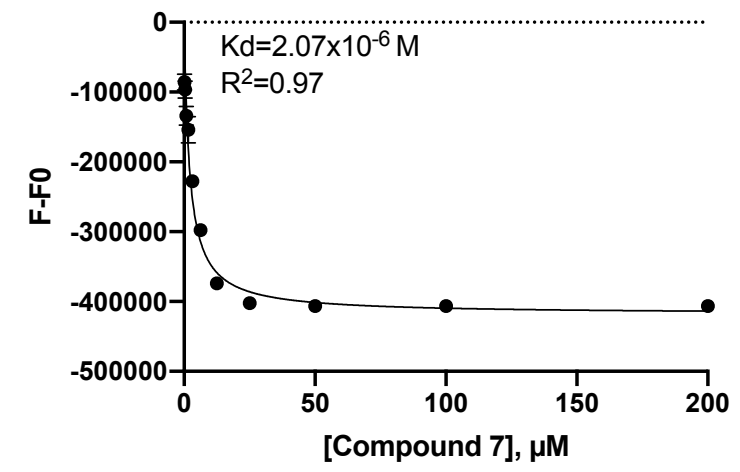

C.

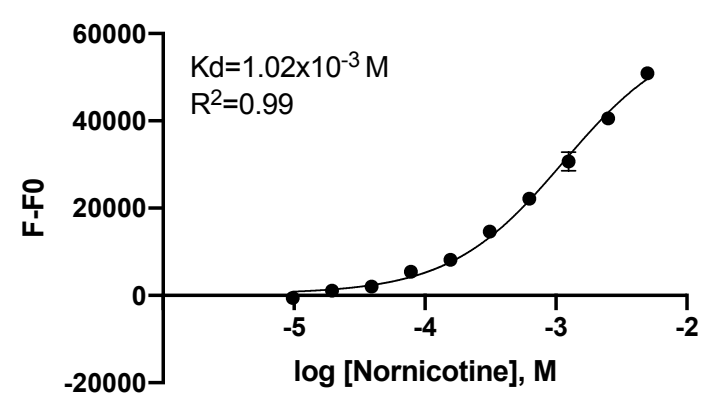

b.

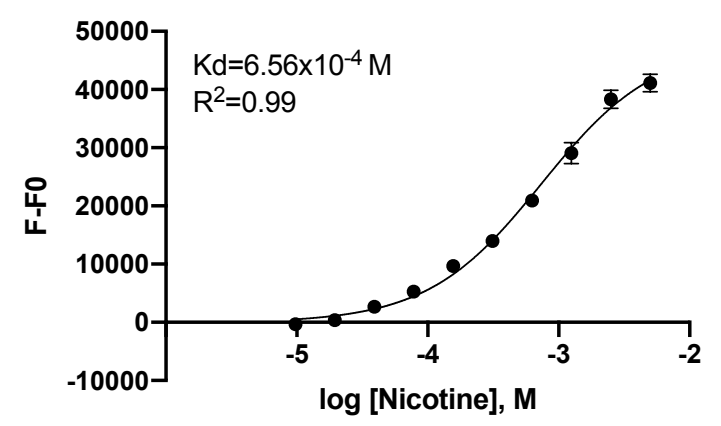

d.

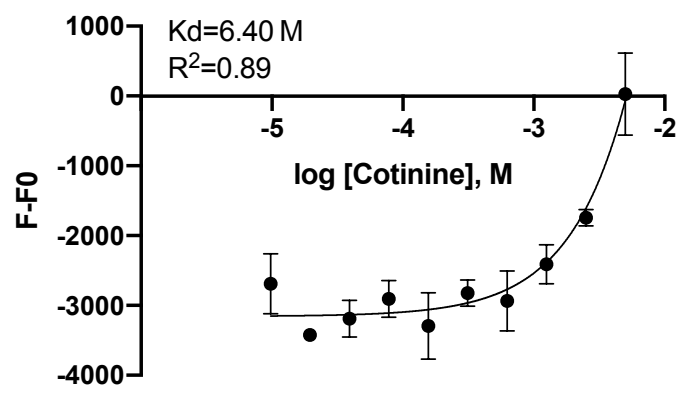

Figure S21: Fluorescence based studies of compound 7 with nicotine, nornicotine and cotinine. a) The direct titration of LCG $(0.25 \mu \mathrm{M})$ with compound $7(0-200 \mathrm{mM})$, and the competitive titrations of b) nicotine $(0-5 \mathrm{mM}), \mathrm{c})$ nornicotine $(0-5 \mathrm{mM})$, and d) cotinine $(0-5 \mathrm{mM})$ titrated into the host-LCG complex ( $5 \mu \mathrm{M}$ host, $0.25 \mu \mathrm{M} \mathrm{LCG}$ ). 


\section{4. ${ }^{1} \mathrm{H}$ NMR titration between compound 1-7 and nicotine}

The NMR titrations are analysed using: http://supramolecular.org. The data was fitted in the bindfit-host-guest binding, to NMR 1:1. The method used was Nelder-Mead, the initial values are subtracted. The links to the fitted data is provided, here the dissociation constants and the maximum chemical shift of the protons can be found. When one of the protons overlapped with another NMR-signal, that proton wasn't used to calculate the binding constant. The percent error of the mean binding constant is propagated by equation 1 . Where ' $x$ ' is the errors of the individual binding constant and ' $n$ ' is the number or measurements.

$$
\text { error }=\frac{\sqrt{(\delta x)^{2}+(\delta x)^{2}}}{\sqrt{(n)}}
$$

Equation 2 shows the error propagation for $\mathrm{sCx} 4$.

$$
\text { error }=\frac{\sqrt{(7.004)^{2}+(6.226)^{2}}}{\sqrt{(2)}}
$$

4.1. ${ }^{1} \mathrm{H}$ NMR titration between compound 1 (sCx4) and nicotine

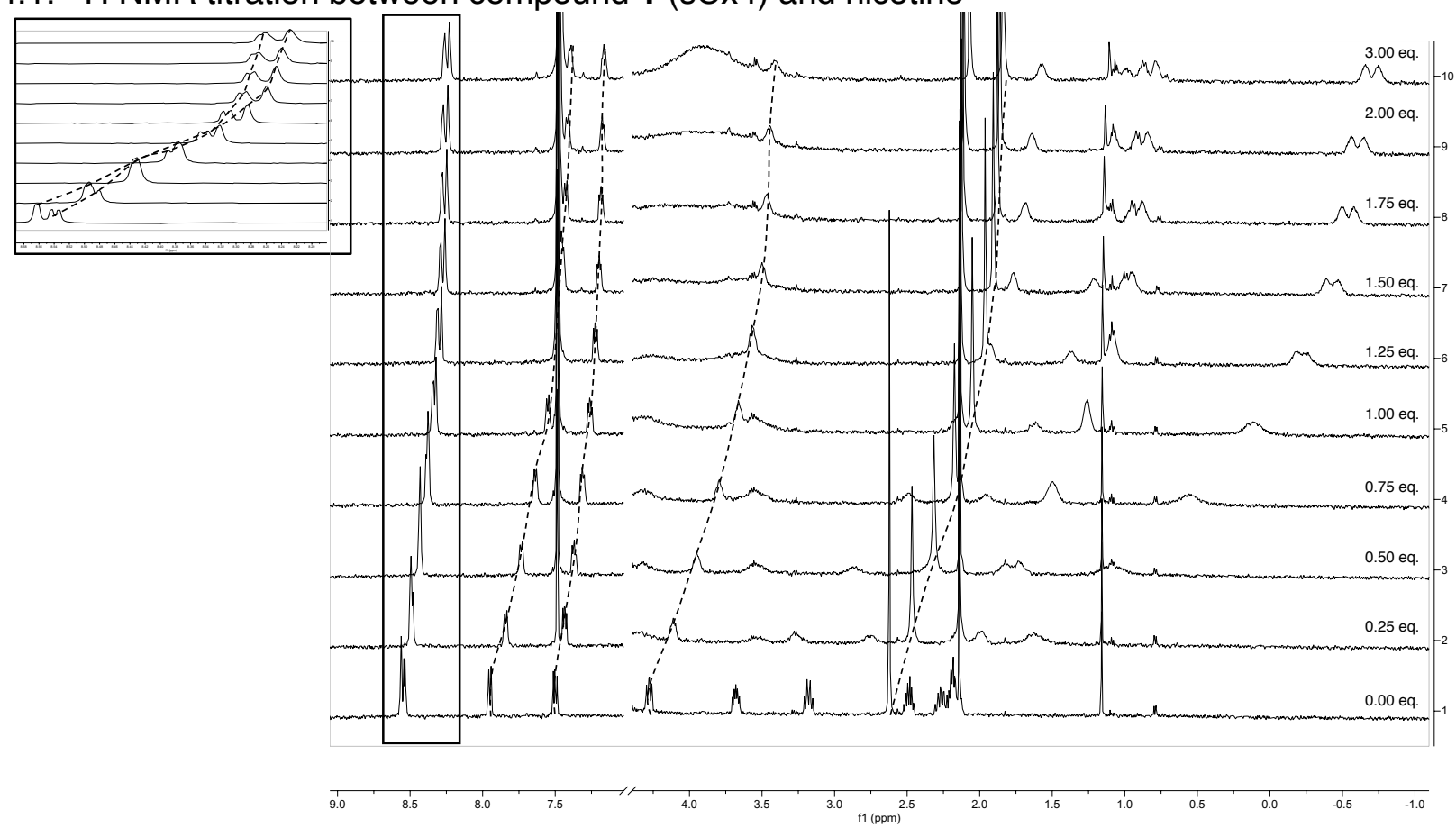

Figure S22: ${ }^{1} \mathrm{H}$ NMR spectrum of compound nicotine $(0.0005 \mathrm{M})$ titrated with compound 1 (0-3 equivalents) in deuterated phosphate buffer (0.05 M, pH 7.4), $500 \mathrm{MHz}$

http://app.supramolecular.org/bindfit/view/b47b6dc6-8763-4f29-9408-7ad8cdeb9e6a http://app.supramolecular.org/bindfit/view/b2479a00-2f46-4823-8fe1-1d693add9ddd 
4.2. ${ }^{1} \mathrm{H}$ NMR titration between compound 2 (1-formyl) and nicotine

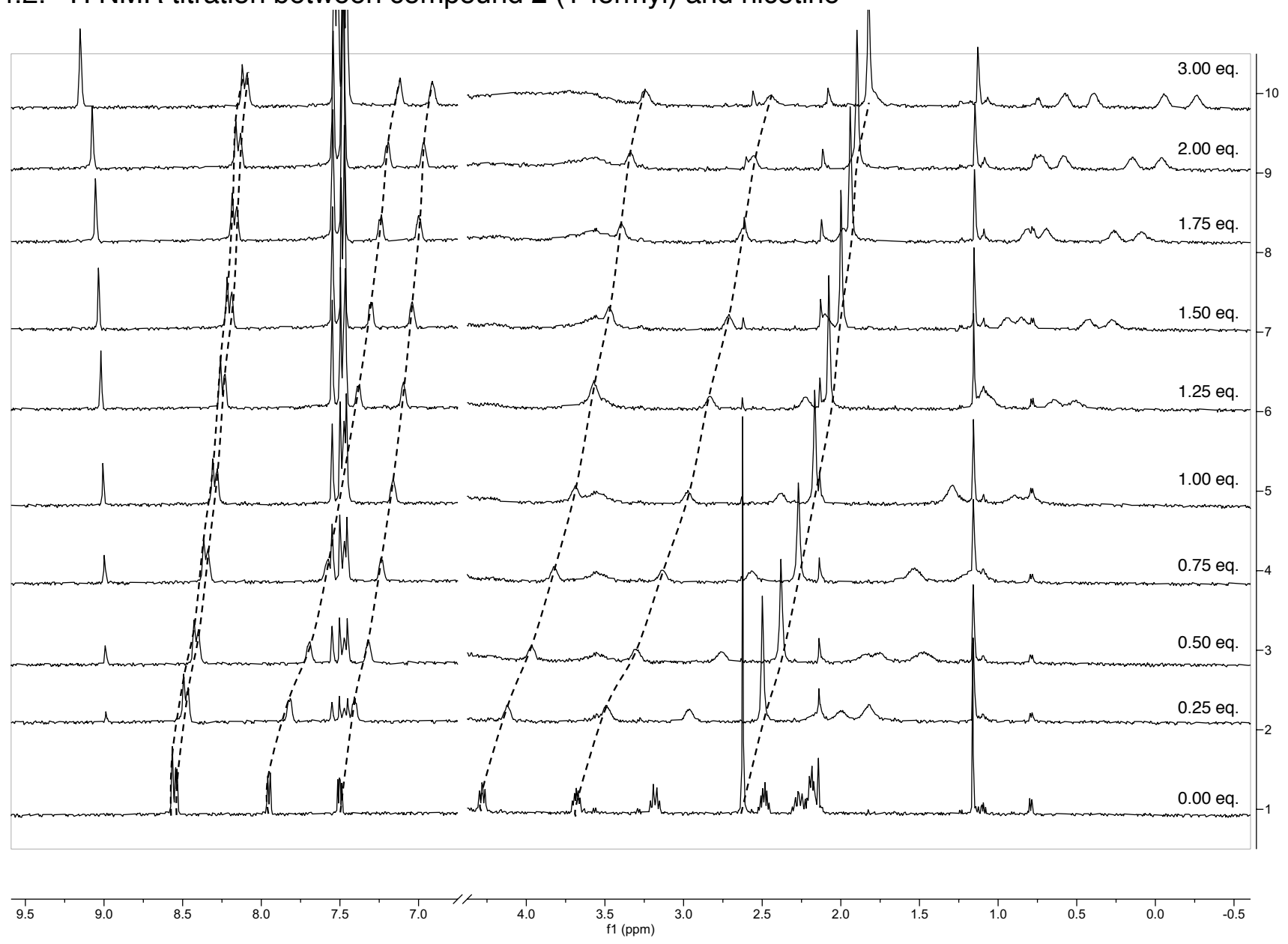

Figure S23: ${ }^{1} \mathrm{H}$ NMR spectrum of compound nicotine $(0.0005 \mathrm{M})$ titrated with compound 2 (0-3 equivalents) in deuterated phosphate buffer $(0.05 \mathrm{M}, \mathrm{pH} 7.4), 500 \mathrm{MHz}$

http://app.supramolecular.org/bindfit/view/9e41cbcd-9b5d-41ed-b936-21b22499c297 http://app.supramolecular.org/bindfit/view/fofe1bb5-a6cf-4e1f-a585-b370fcd3fb03 
4.3. ${ }^{1}$ H NMR titration between compound 3 (1-nitro) and nicotine

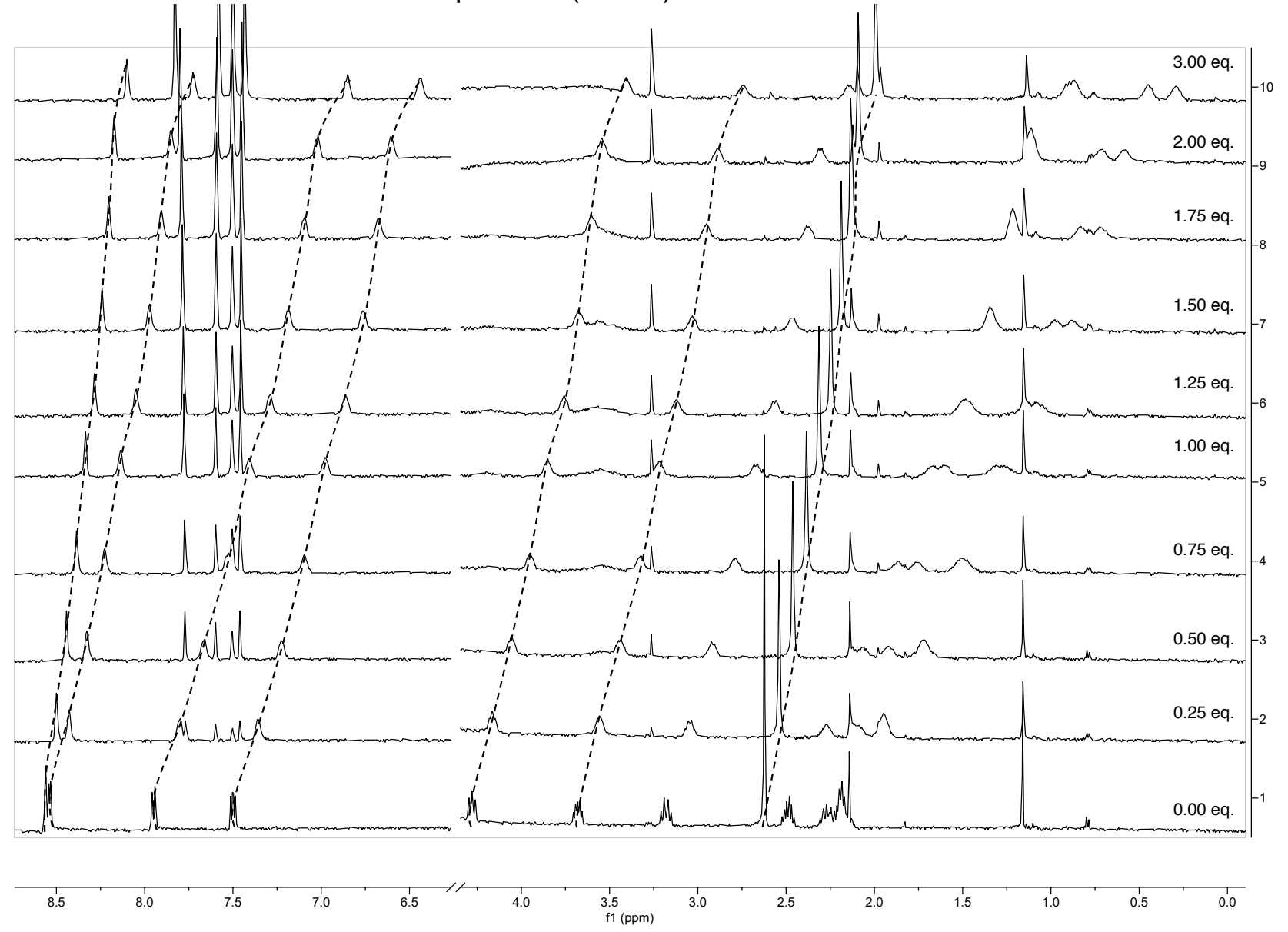

Figure S24: ${ }^{1} \mathrm{H}$ NMR spectrum of compound nicotine $(0.0005 \mathrm{M})$ titrated with compound 3 (0-3 equivalents) in deuterated phosphate buffer $(0.05 \mathrm{M}, \mathrm{pH} 7.4), 500 \mathrm{MHz}$

http://app.supramolecular.org/bindfit/view/cc7d02cc-beef-49a7-91f8-9de6901c751d http://app.supramolecular.org/bindfit/view/15b96050-e269-4b93-a443-0e5e091f75d6 
4.4. 1H NMR titration between compound 4 (1,3-formyl) and nicotine

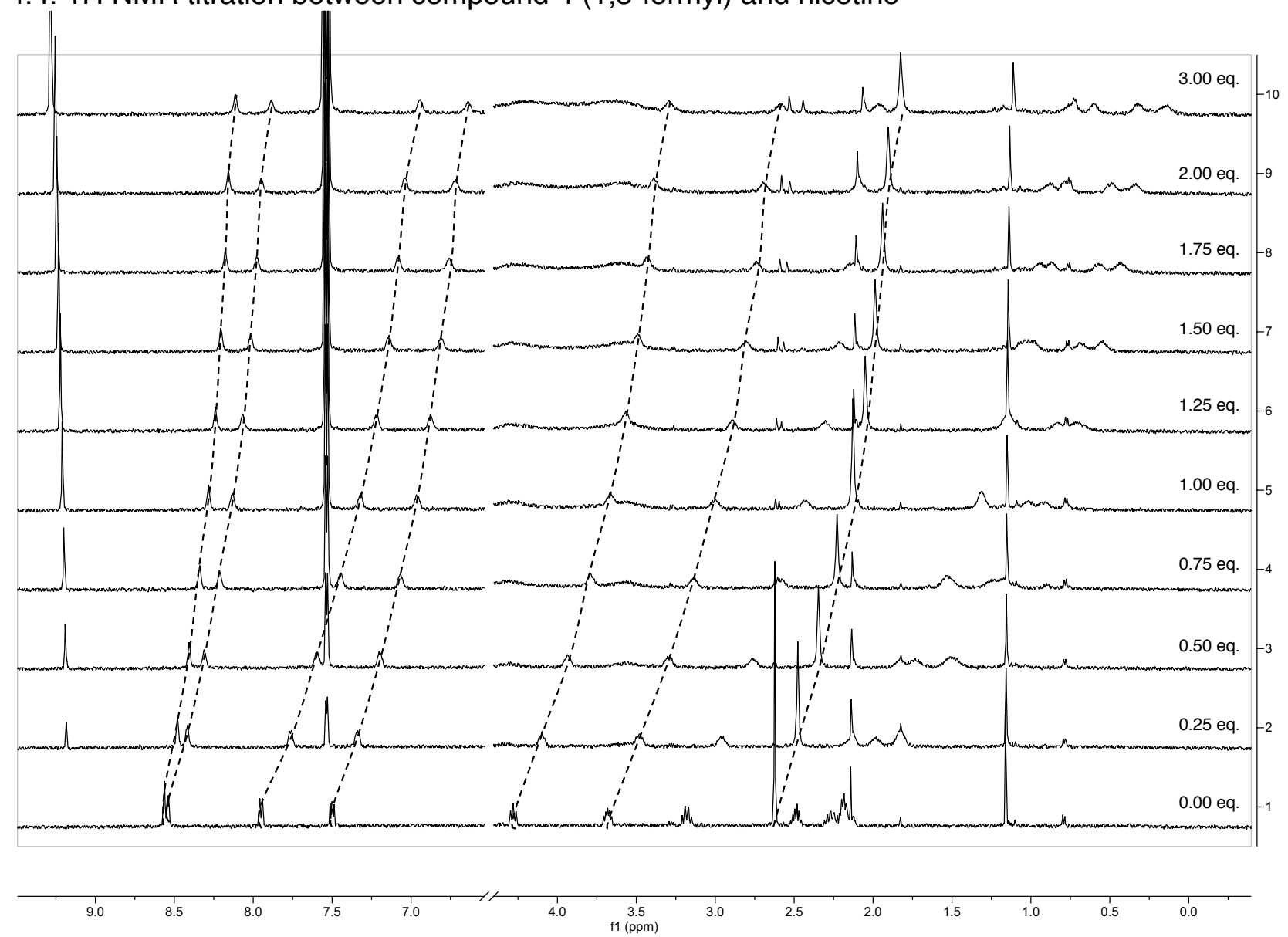

Figure S25: ${ }^{1} \mathrm{H}$ NMR spectrum of compound nicotine $(0.0005 \mathrm{M})$ titrated with compound 4 (0-3 equivalents) in deuterated phosphate buffer (0.05 M, pH 7.4), $500 \mathrm{MHz}$

http://app.supramolecular.org/bindfit/view/e3afe697-a414-4a44-944a-3669ed909ad7

http://app.supramolecular.org/bindfit/view/b881418b-7039-43be-9693-68dd80ba740b 
4.5 1H NMR titration between compound 5 (1,3-nitro) and nicotine
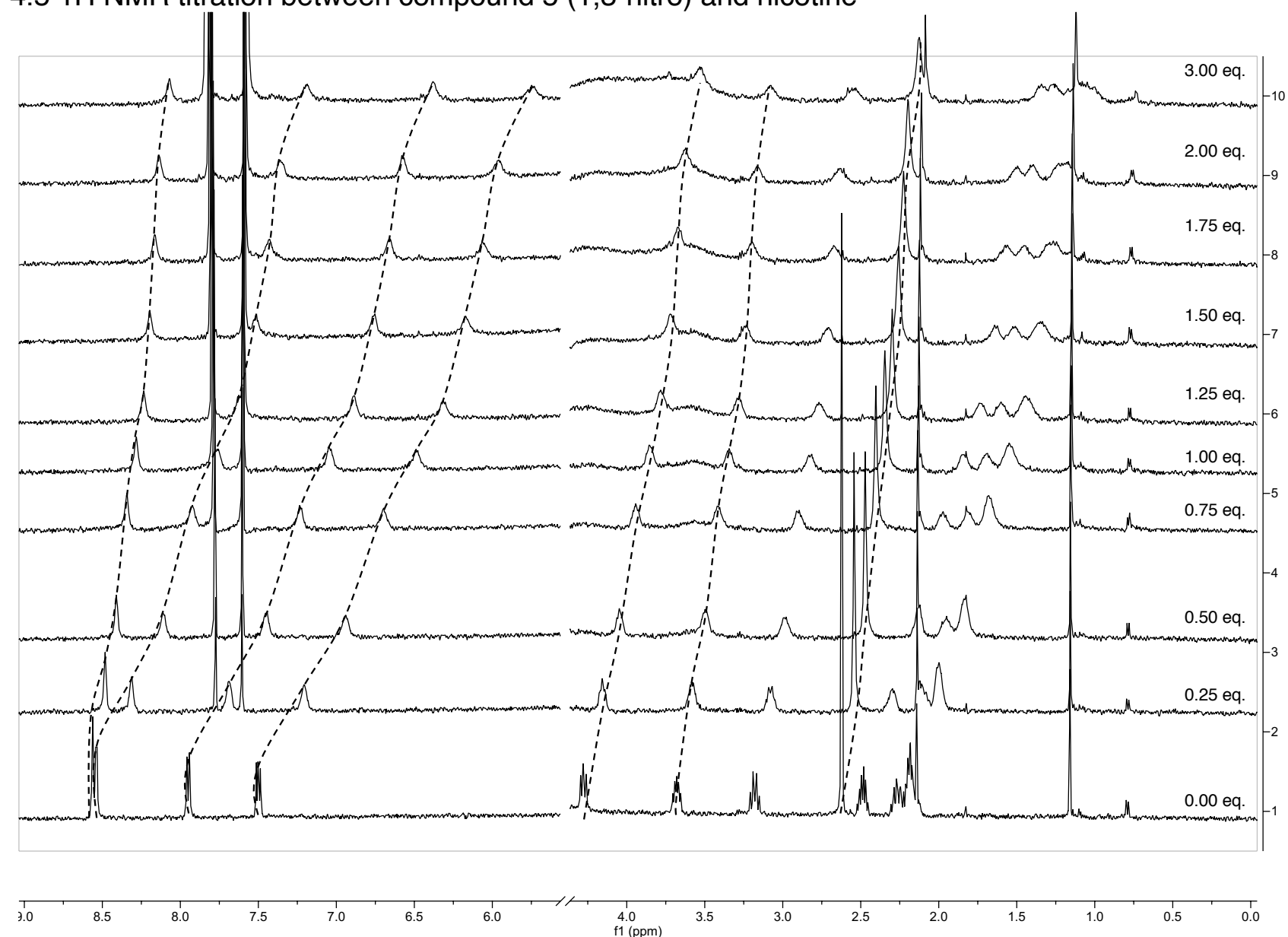

Figure S26: ${ }^{1} \mathrm{H}$ NMR spectrum of compound nicotine $(0.0005 \mathrm{M})$ titrated with compound $5(0-3$ equivalents) in deuterated phosphate buffer (0.05 M, pH 7.4), $500 \mathrm{MHz}$

http://app.supramolecular.org/bindfit/view/01575fe5-4fd6-4303-8783-6cb41e31e619 http://app.supramolecular.org/bindfit/view/88df5a0b-c365-4c67-89a2-5ae7e024e813 
4.6. 1H NMR titration between compound 6 (1,2-formyl) and nicotine
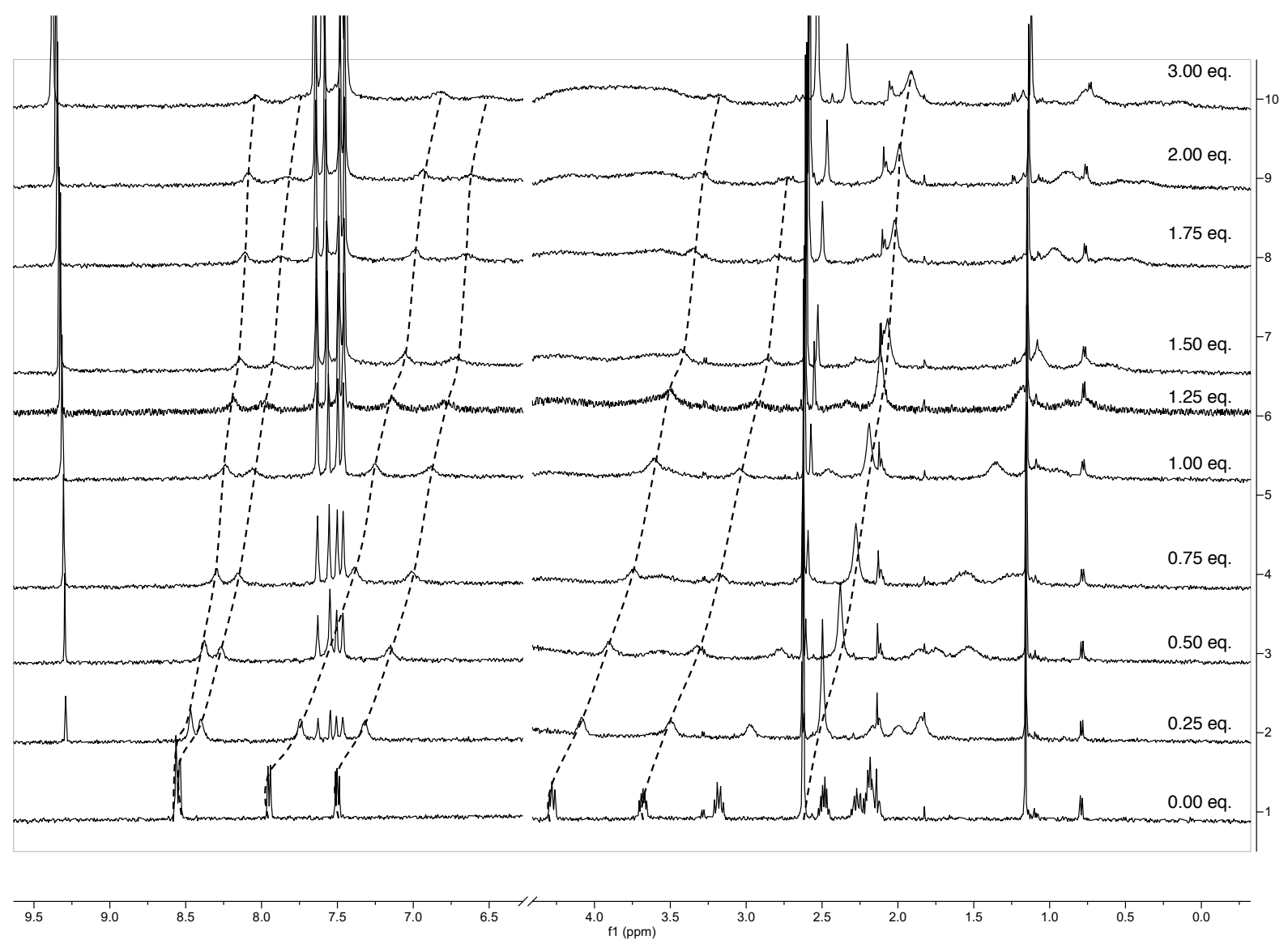

Figure S27: ${ }^{1} \mathrm{H}$ NMR spectrum of compound nicotine $(0.0005 \mathrm{M})$ titrated with compound $6(0-3$ equivalents) in deuterated phosphate buffer (0.05 M, pH 7.4), $500 \mathrm{MHz}$

http://app.supramolecular.org/bindfit/view/9e41cbcd-9b5d-41ed-b936-21b22499c297 http://app.supramolecular.org/bindfit/view/f0fe1bb5-a6cf-4e1f-a585-b370fcd3fb03 
4.7. 1H NMR titration between compound 7 (1,2-nitro) and nicotine
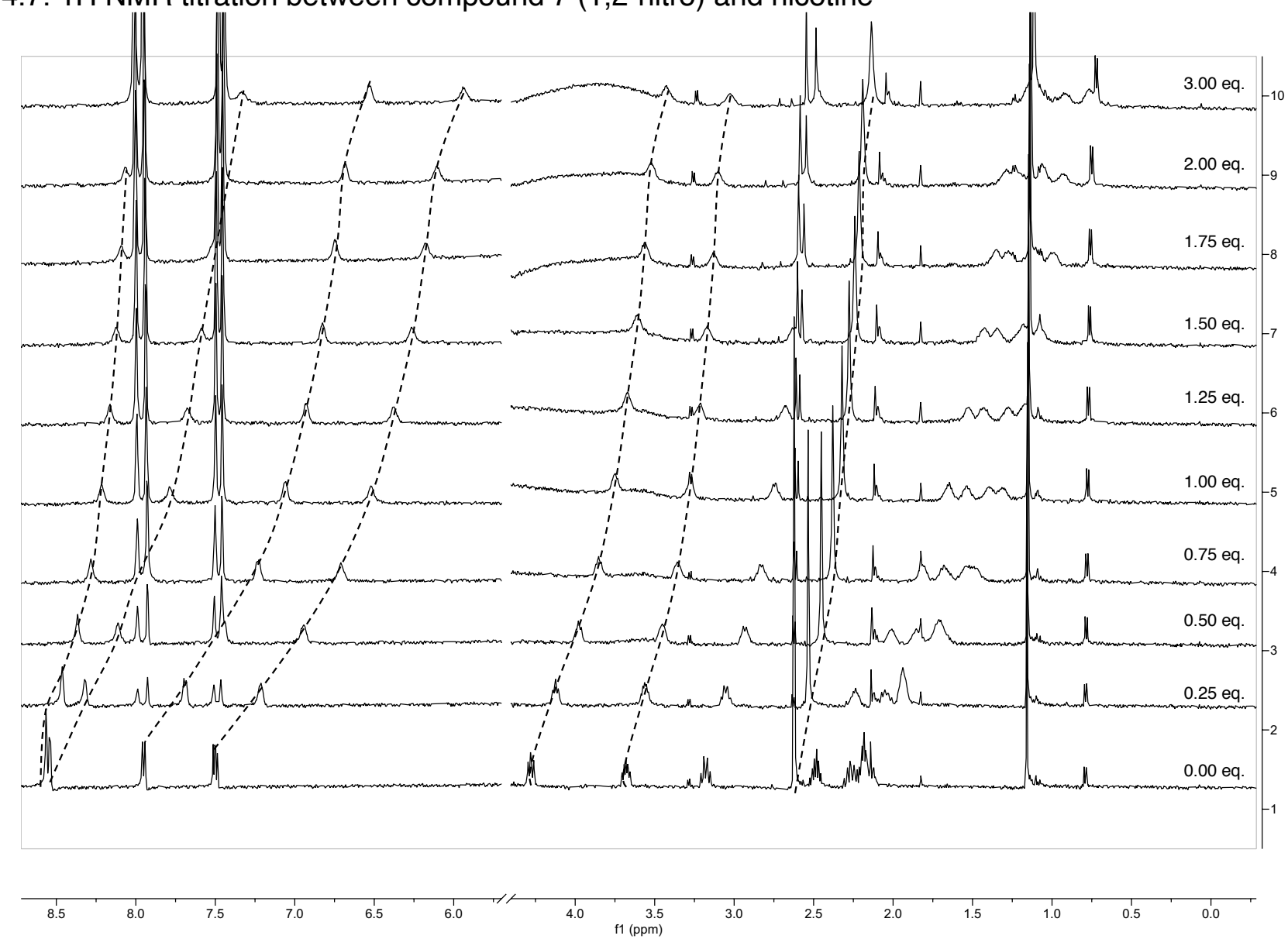

Figure S28: ${ }^{1} \mathrm{H}$ NMR spectrum of compound nicotine $(0.0005 \mathrm{M})$ titrated with compound 7 (0-3 equivalents) in deuterated phosphate buffer (0.05 M, pH 7.4), $500 \mathrm{MHz}$

http://app.supramolecular.org/bindfit/view/b78dfc30-c67f-41f9-8bc2-bd7dc71ff9a9

http://app.supramolecular.org/bindfit/view/ed8fa055-2c54-4fba-b9e2-891e82930b40 